\title{
Seasonal-Mean Hydrography and Circulation in the Gulf of St. Lawrence and on the Eastern Scotian and Southern Newfoundland Shelves
}

\author{
Guoqi Han, John W. Loder, and Peter C. Smith \\ Fisheries and Oceans Canada, Bedford Institute of Oceanography, Dartmouth, Nova Scotia, Canada
}

(Manuscript received 18 November 1997, in final form 13 July 1998)

\begin{abstract}
The climatological seasonal-mean hydrography and circulation in the Gulf of St. Lawrence and on the eastern Scotian and southern Newfoundland shelves are studied by reconstructing high-resolution temperature, salinity, and density fields for four seasons and numerically computing the associated circulation fields. The current fields are obtained from a three-dimensional diagnostic model, forced by baroclinic pressure gradients, seasonal wind stresses, and additional barotropic inflows across the Strait of Belle Isle and southern Newfoundland shelf upstream boundaries. The hydrographic fields suggest strong gulf-shelf interconnections, including outflow of relatively fresh surface water from the gulf to the eastern Scotian shelf, penetration of slope water at depth onto the shelves and into the gulf, and flow into the gulf through the Strait of Belle Isle. The circulation is generally cyclonic in the gulf, reinforced by inflows of Labrador and Newfoundland shelf water through the Strait of Belle Isle and Cabot Strait, while the circulation over the Scotian shelf is dominated by the southwestward shelf-break flow of water from the gulf and the Newfoundland shelf, with weaker flows from the gulf onto the inner and midshelf. Known major flow features such as the Gaspé Current, Cabot Strait outflow and inflow, and the Nova Scotian Current are realistically reproduced, and can be attributed to a combination of baroclinic pressure field and boundary inflow forcing. The model solutions are in approximate quantitative agreement with observed elevations, currents, and transports but with differences and notable uncertainties in some areas.
\end{abstract}

\section{Introduction}

The eastern Scotian and southern Newfoundland shelves are separated by the Laurentian Channel (Fig. 1), which extends into the Gulf of St. Lawrence through Cabot Strait and provides a major pathway for water exchange between the Atlantic Ocean and the gulf. This region is a confluence zone for continental runoff into the gulf, Labrador Current water from the north, and offshore slope water, and consequently has large spatial and temporal variations in hydrographic properties and circulation (e.g., Loder et al. 1998). An improved description and understanding of the regional hydrography and circulation at this important flow junction are of fundamental physical oceanographic importance, both to the local gulf-shelf system as well as to climatic variability farther downstream in the northwest Atlantic's subpolar coastal current (Chapman and Beardsley 1989). Furthermore, and providing the specific motivation for this study, increased knowledge of the local physical environment is of importance to current regional fisheries issues such as the seasonal supply of

Corresponding author address: Dr. Guoqi Han, Coastal Ocean Science, Bedford Institute of Oceanography, Post Office Box 1006, Dartmouth, NS B2Y 4A2, Canada.

E-mail: ghan@emerald.bio.dfo.ca zooplankton and other food sources from the Gulf of St. Lawrence to the Scotian shelf (Herman et al. 1992; Sameoto and Herman 1992) and the seasonal distribution and migration patterns of cod and redfish, which congregate in the Cabot Strait region in winter and disperse throughout the region for the rest of the year (Morin et al. 1994; Campana et al. 1995). Previous studies on the regional hydrography and seasonal circulation have been conducted separately for the gulf (see Koutitonsky and Bugden 1991 for a recent review) and shelf regions (e.g., Han et al. 1997; Loder et al. 1997), so the present work is focused on properties and dynamics of the coupled gulf-shelf system, as well as regional updates in light of newly available observational data and circulation models.

A number of studies have been conducted on the structure and origin of water masses in the gulf and shelf regions (e.g., Hachey 1942; Petrie et al. 1988; Koutitonsky and Bugden 1991; Gilbert and Pettigrew 1997). Climatological temperature and salinity statistics have been compiled for most areas (e.g., Drinkwater and Trites 1986, 1987; Petrie et al. 1996), and interpretative analyses of the structure and seasonal variation have been made for some (e.g., McLellan 1954; Bugden 1981; Petrie and Drinkwater 1993; Umoh and Thompson 1994). These studies have shown that the vertical structure of the regional hydrography generally varies 




FIG. 1. Map showing the study domain, bathymetry, and section locations; isobaths shown are 100, 200, 1000, and $3000 \mathrm{~m}$. The Gaspé, Cabot Strait, Burin, and Banquereau sections are shown in solid lines. SNSI and SNS-SB are the inner and shelf-break segments of the upstream SNS boundary. L1 and L2 are the inner and outer segments of the Liscomb line on the downstream ESS boundary.

from a two-layer system in winter, when relatively cool and fresh water overlies slope-derived water, to a threelayer system in summer, when a warm surface layer develops leaving a cool intermediate layer below. Nearsurface water properties have substantial spatial variations reflecting differences in the continental and oceanic source waters, while the near-bottom waters have distinct spatial variations associated with the vertical hydrographic structure in combination with water depth changes (McLellan 1954). These variations provide valuable tracer information on the circulation patterns, as well as contributions to circulation through associated baroclinic pressure gradients.

Observations and interpretation of the circulation in this region have been limited compared to adjacent shelf regions. Moored current measurements have been made in only a few subareas, and there have been few (if any) modern drifter studies. For the gulf, estimates of the circulation pattern are available for the near-surface waters in summer using drifter and moored measurements (Trites 1972), for the surface waters in all seasons from geostrophic calculations using climatological monthly density fields (El Sabh 1976), and for the upper $50 \mathrm{~m}$ in all seasons from heat and salt budgets (Bugden 1981). There have been several numerical modeling studies on the wind-driven seasonal circulation (see Koutitonsky and Bugden 1991), and prognostic model studies of the seasonal circulation have recently been initiated (F. Saucier 1996, personal communication; K. Thompson 1997, personal communication). For the eastern Scotian and southern Newfoundland shelf regions, information on the shelf-scale circulation is largely limited to sea surface slope estimates from altimetry (Han et al. 1993) and recent barotropic and baroclinic model studies of seasonal circulation (Han et al. 1997; Loder et al. 1997). The most extensive information on circulation has come from three key subareas (Fig. 1) using a variety of techniques: the Strait of Belle Isle connecting the northeast gulf to the Labrador shelf (e.g., Dawson 1913; MacGregor 1956; Petrie et al. 1988), the lower St. Lawrence estuary and northwest gulf (e.g., El Sabh and Silverberg 1990; Tang 1980), and Cabot Strait (e.g., Lawrence 1968; El Sabh 1977). However, there are inconsistencies among the results from these studies, such as between El Sabh's (1977) geostrophic transport estimates and summertime moored current measurements in Cabot Strait (Trites 1972) and between the net transport estimates through the Strait of Belle Isle (Petrie et al. 1988) and Cabot Strait (El Sabh 1977). There is a clear need for further interpretative studies that synthesize the expanding observational datasets from various parts of the gulf-shelf system and, in particular, provide dynamically based extrapolations from the moored measurement sites to other areas. 

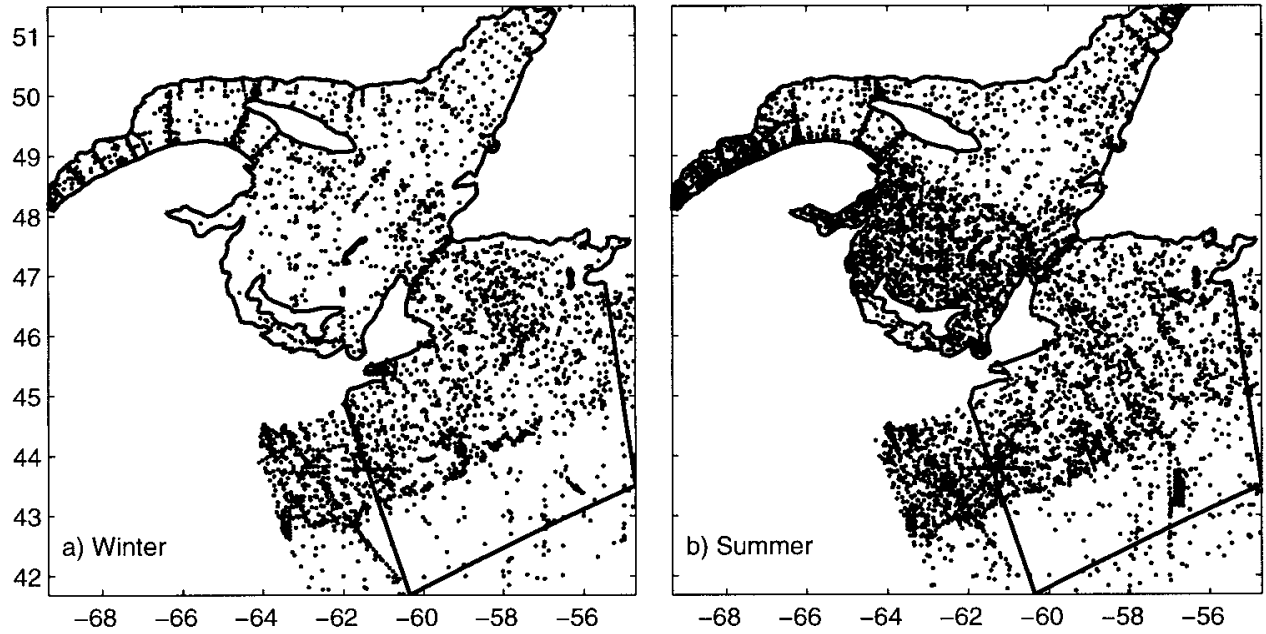

FIG. 2. The distribution of observational density data is in the depth interval 5-25 $\mathrm{m}$ for 6-month periods encompassing (a) winter (Nov-Apr) and (b) summer (May-Oct).

In this paper, we use a high-resolution reconstruction of the climatological seasonal-mean hydrography and a 3D diagnostic numerical model to examine the seasonalmean circulation for the coupled gulf-shelf system comprising the Gulf of St. Lawrence and the eastern Scotian and southern Newfoundland shelves. The combined gulf-shelf domain together with the model variable grid size allows examination of connections among shelf water, slope water, and gulf water in this region, on both broad (gulf, shelf) and topographic (50-100 km for channels, banks, and basins) scales. Our goals are to develop a quantitative observationally based representation of the seasonal variations in 3D hydrography and circulation in the region, to evaluate the consistency of this circulation with moored current measurements, and to investigate some underlying aspects of the circulation such as the role of flows through key areas (such as straits and model boundaries) and the extent of vertical versus horizontal structuring of the circulation.

We start in section 2 with brief descriptions of the optimal interpolation procedure used in estimating the hydrographic fields, the 3D finite-element circulation model and its forcing, and the moored current measurements. The distribution of hydrographic properties is described in section 3 , and the circulation model results are presented and compared with the moored measurements in section 4. Several aspects of the overall circulation are discussed in section 5, and we conclude with a brief summary in section 6 .

\section{Methodology}

\section{a. Reconstruction of hydrographic fields}

The seasonal-mean hydrographic fields were estimated following the approach of Loder et al. (1997) (also see Han et al. 1997). Coincident temperature and salinity observations from the historical database at the
Bedford Institute of Oceanography were used to compute density. Conductivity-temperature-depth (CTD) data were then subsampled at standard vertical positions (10-m intervals for $0-60 \mathrm{~m}, 25-\mathrm{m}$ intervals for 75-250 $\mathrm{m}, 50-\mathrm{m}$ intervals for $300-500 \mathrm{~m}, 100-\mathrm{m}$ intervals for $600-1200 \mathrm{~m}$, and 500-m intervals for $1500-5000 \mathrm{~m})$, yielding a relational database in four dimensions (two horizontal coordinates, depth, and time). Observations (Fig. 2) were distributed across the eastern Scotian and southern Newfoundland shelves, the Gulf of St. Lawrence and adjacent regions, and mostly scattered in time between 1950 and 1995. Poorest coverage was generally in winter and in the northeast gulf, on the southern Newfoundland shelf, and over the continental slope and deep ocean.

Climatological mean temperature, salinity, and density fields for each of four seasons (nominally JanuaryFebruary, April-May, July-August, and October-November representing winter, spring, summer, and fall, respectively) were estimated at specified grid points in four-dimensional space using optimal linear interpolation (Bretherton et al. 1976). This procedure provides estimates of the mean fields, from their nearest neighbor data points based on separation distances scaled by specified correlation scales in an assumed covariance function. The horizontal grid points were the 7734 variably spaced nodes of a triangular finite element mesh covering the Gulf of St. Lawrence, eastern Scotian shelf (ESS), and southern Newfoundland shelf (SNS) (Fig. 3 ), with high resolution in shallow areas and in areas of small topographic length scale $(h / \nabla h, h$ is the local water depth). Typical grid spacing in the gulf and shelf region is $2-3 \mathrm{~km}$, with a maximum of about $15 \mathrm{~km}$ in the deep Laurentian Channel. The mesh has open boundaries across the lower St. Lawrence estuary (LSLE), the Strait of Belle Isle (SBI), the SNS off the Burin Peninsula, and the ESS off Liscomb, and extends offshore 


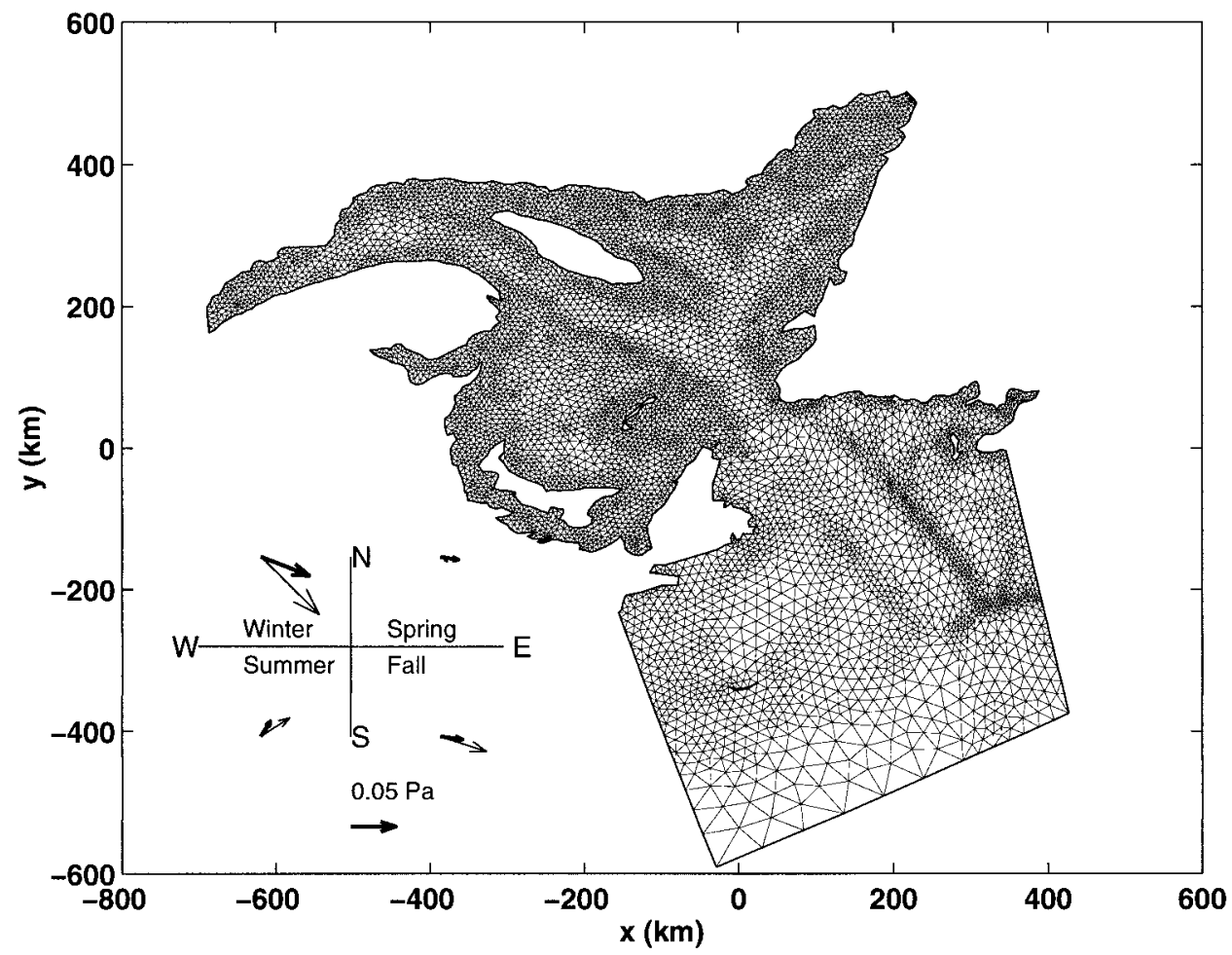

FIG. 3. The horizontal finite element grid (core3) used for the hydrographic fields and in the numerical model. The model origin is at $47^{\circ} \mathrm{N}, 60^{\circ} \mathrm{W}$. Also shown are the magnitude and direction of the climatological seasonal-mean wind stresses at Sable Island (thick arrows) and Magdalen Shallows (thin arrows).

about $200 \mathrm{~km}$ beyond the shelf break. The vertical grid points for the estimated fields were levels of constant depth corresponding to the standard depths of the subsampled CTD data. The fields were also estimated at levels below the seafloor, with vertical interpolation then used to obtain near-bottom values. The temporal grid points were chosen as seasonal midtimes ( $1 \mathrm{Feb}, 1$ May, 1 Aug, and 1 Nov), with data from all years then used in estimating the climatological fields. Data used in the interpolation were weighted about grid points and seasonal midtimes using the covariance function and correlation scales, specified as in Loder et al. (1997), with horizontal variations in the horizontal correlation scales based on the water depth and local bathymetric gradient vector, the vertical correlation scale increasing with depth, and the time correlation scale set at 60 days.

\section{b. Circulation model}

The 3D circulation associated with baroclinic (and associated barotropic) pressure gradients, surface wind stresses, and additional open boundary inflows was computed using FUNDY5 (Naimie and Lynch 1993), a diagnostic finite element numerical model described in Lynch et al. (1992). The model uses a harmonic method to solve the linearized 3D hydrodynamical equations with hydrostatic and Boussinesq assumptions and a vertical eddy viscosity closure. Horizontally varying bot- tom friction coefficients and vertical eddy viscosity values were specified from a solution of Naimie et al.'s (1994) iterative nonlinear two-frequency model (also see Han et al. 1997) for the barotropic $M_{2}$ tide and associated mean flow, with background values included to represent the contribution of unmodeled flow components. The background value of $0.00035 \mathrm{~m} \mathrm{~s}^{-1}$ was used for the bottom friction coefficient by assuming a near-bottom current speed of $0.07 \mathrm{~m} \mathrm{~s}^{-1}$ in the unmodeled flow components (i.e., other than $M_{2}$ and mean currents), and the value of $0.002 \mathrm{~m}^{2} \mathrm{~s}^{-1}$ for the vertical eddy viscosity by assuming a depth-averaged unmodeled current speed of $0.1 \mathrm{~m} \mathrm{~s}^{-1}$. For most of the domain, the resulting bottom friction coefficient was around $0.0005 \mathrm{~m} \mathrm{~s}^{-1}$, while the (vertically uniform) eddy viscosity ranged from 0.002 to $0.005 \mathrm{~m}^{2} \mathrm{~s}^{-1}$, except in some shallow areas, such as Jacques Cartier Strait where maximum values ranged up to $0.0022 \mathrm{~m}$ $\mathrm{s}^{-1}$ and $0.058 \mathrm{~m}^{2} \mathrm{~s}^{-1}$.

The model's horizontal mesh is the same as that on which the hydrographic fields were estimated (Fig. 3), while its vertical mesh has 21 variably spaced nodes that lie approximately on constant $\sigma(=z / h)$ levels (where $z$ is the vertical coordinate) with minimum spacing of $2.5 \mathrm{~m}$ at the surface and bottom. The model uses full-depth topography (from a database with about 7-km resolution for the gulf and shelf), contrasting the deepocean false bottom used in Han et al. (1997) and Loder 
et al. (1997). The LSLE boundary is approximated as a land boundary, which should not have significant influences on the diagnosed circulation since the St. Lawrence River discharge (climatological monthly peak of $23000 \mathrm{~m}^{3} \mathrm{~s}^{-1}$ ) is relatively small from the perspective of volume transport.

\section{c. Model forcing}

A combination of model solutions with baroclinic and local wind forcing, and barotropic model solutions forced only by upstream inflows is used to obtain composite seasonal-mean flow fields. The sea level setup at the SNS boundary due to wind forcing over the SNS is estimated to be small $(-1.3 \mathrm{~cm}$ at Burin based on arrested topographic wave theory, in response to an alongshelf stress of $0.05 \mathrm{~Pa}$ ), and is therefore not included. We also neglect tidally induced residual velocities, which the above-mentioned two-frequency tidal solution indicates to be a relatively small contributor to the gulf-, shelf-, and topographic-scale circulation in the region. Although sea ice formation and melting, surface heat fluxes, and St. Lawrence River discharge are not explicitly specified, their effects on the circulation are included through their contributions to the observed density fields.

The baroclinic/wind model solutions are forced by the baroclinic pressure gradients associated with the climatological density fields and by spatially uniform seasonal-mean wind stresses. The horizontal pressure gradients on the model's vertical mesh are obtained from vertical interpolation of the pressure gradients computed on the level surfaces of the optimal interpolation grid. The wind stresses are computed, as in Han et al. (1997), from hourly wind measurements at Sable Island on the eastern Scotian shelf during 1953-86, which have been shown to be representative of low-frequency winds over most of the Scotian shelf (Smith 1987). The climatological mean stresses (Fig. 3) have seasonal variations in both magnitude and direction, with the winter stress being stronger and directed more cross-shelf (offshore) than the stresses during the other seasons. Although the mean wind stresses in the Gulf of St. Lawrence have significant spatial variability (Koutitonsky and Bugden 1991) and quantitative differences from the Sable Island stresses (see the mean geostrophic wind stresses at the Magdalen Shallows in Fig. 3), we use the latter as an approximation for the entire model domain since the seasonal-mean wind-driven barotropic circulation is small compared with the density-driven and remotely forced circulation over most of the domain (see section 4). This approximation is supported by model solutions (not shown) forced by the winter wind stresses from Sable Island or the Magdalen Shallows, which show little significant transport difference in the gulf (but indicate that wind forcing is of comparable importance to baroclinic and remote forcing in driving winter-mean circulation in shallow areas such as the Magdalen Shallows).

For each season, a regional baroclinic/wind solution is obtained first with steric conditions specified on the SBI, SNS, and offshore boundaries, estimated from the density field to give no normal geostrophic flow at the seafloor. These steric conditions are specified in the form of elevations on the SNS and offshore boundaries, and depth-integrated velocities on the SBI boundary (to allow natural adjustment of the elevation difference between the SBI and SNS boundaries). The specified downstream (ESS) boundary condition is obtained from a similar model solution but on an extended domain (Han et al. 1996). The condition of no normal depthintegrated flow is implemented on the land (and LSLE) boundaries.

Barotropic solutions with additional inflows specified at the SBI and SNS boundaries are computed to represent remote barotropic forcing (e.g., Greenberg and Petrie 1988). Petrie et al. (1988) found from direct current measurements, hydrographic data analysis, and monthly mean cross-strait sea level differences that the transport into the gulf through the SBI has a mean summer value of $0.13 \mathrm{~Sv}\left(\mathrm{~Sv} \equiv 10^{6} \mathrm{~m}^{3} \mathrm{~s}^{-1}\right)$ and a mean winter value of $0.3 \mathrm{~Sv}$, with significant interannual variability. In the present study, additional barotropic flows through the SBI are introduced by adding linear sea surface slopes across the strait to the regional baroclinic/ wind solutions, based on Petrie et al.'s (1988) tide gauge observations subject to geostrophic levelling against the moored measurements from the summer of 1980. The resulting cross-strait differences (north side minus south side) are 7.3, 3.3, 0.8, and $9.3 \mathrm{~cm}$ for winter, spring, summer, and fall, respectively. The influences of possible barotropic inflows across the SNS boundary where there is less observational information are examined using specified linear elevation changes on its inner and shelf-break segments (see section 4a). For all the barotropic model solutions, zero elevation is prescribed on the offshore boundary while a geostrophic flow condition is applied on the downstream (ESS) boundary. Zero elevation is prescribed on the SNS boundary for the SBI inflow case, and the geostrophic flow condition is used on the SBI boundary for the SNS inflow cases.

Finally, linear superposition of the baroclinic/wind solutions and the SBI and SNS barotropic inflow solutions provides the base composite circulation fields presented in sections $4 \mathrm{~b}-\mathrm{d}$. Solutions without the SNS barotropic inflow are also discussed in comparison with the base solutions.

\section{d. Moored current measurements}

Monthly mean currents from moored measurements were obtained from a database of monthly current statistics at the Bedford Institute of Oceanography. A minimum of 20 days of data was required for each monthly mean, resulting in means for $43,21,65$, and 15 sites in 
a) Winter

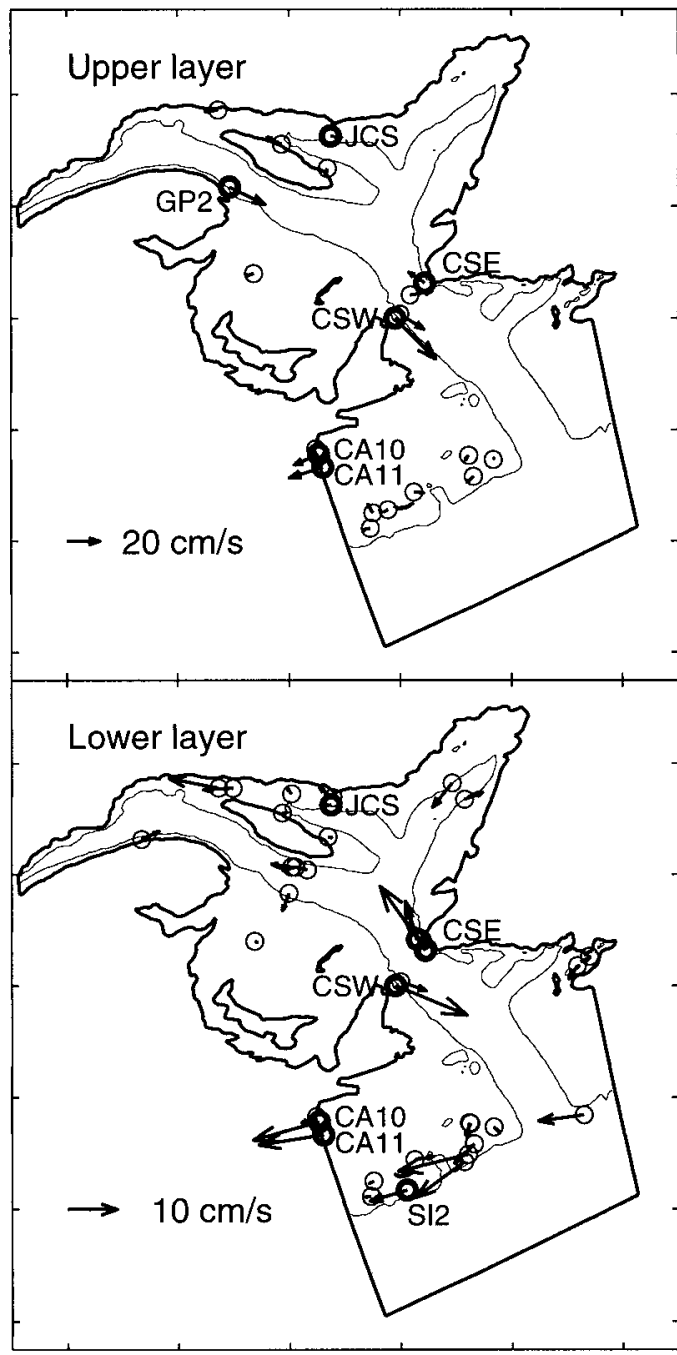

b) Summer

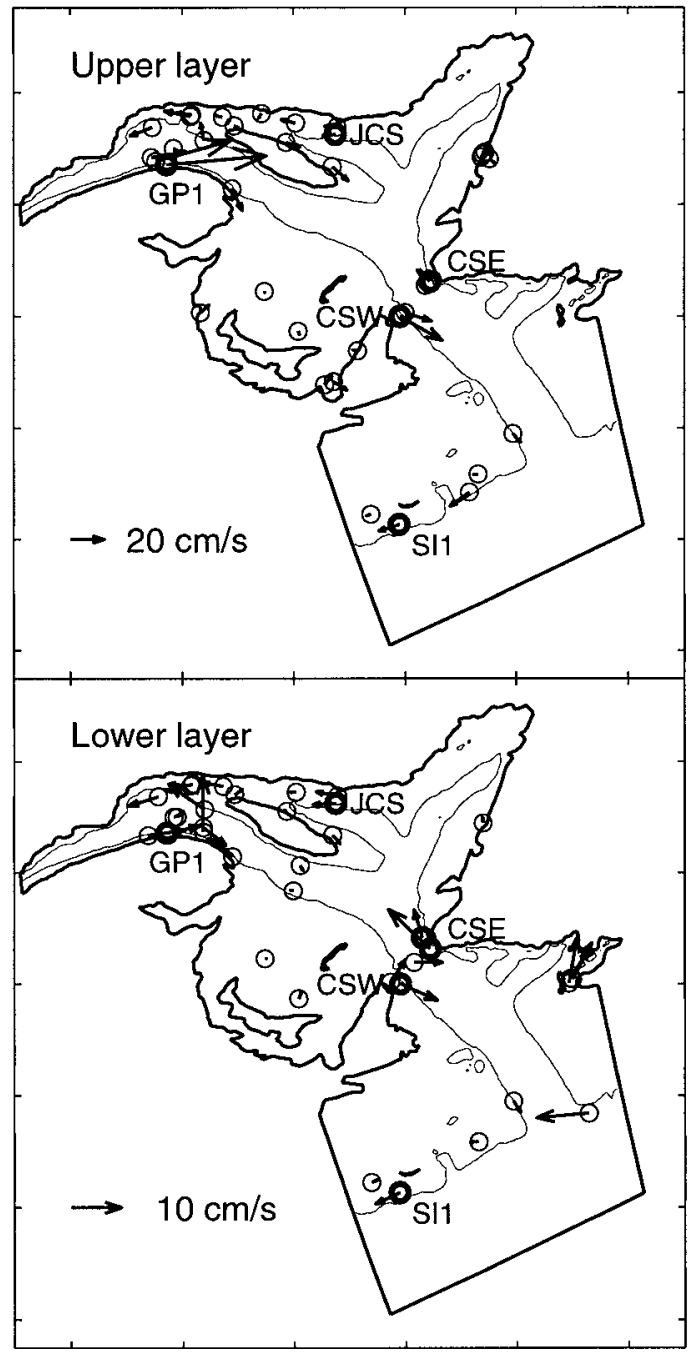

FIG. 4. Bimonthly mean currents from moored measurements for the upper layer (within $30 \mathrm{~m}$ of surface) and lower layer (remainder of the water column), computed by vertical averaging for (a) winter and (b) summer. For clarity, only representative data are shown. The $200-\mathrm{m}$ isobath is included.

the bimonthly seasons of winter, spring, summer, and fall, respectively. Typically, each site has observations from one to three depths in one or two years. For overall comparisons with the model flow fields, seasonal-mean currents and standard deviations were computed for each 3D position with at least two monthly means, by averaging over all months and years in each bimonthly season. This resulted in $76,38,144$, and 37 different 3D positions with seasonal-mean current estimates in the four respective seasons. For comparison, model velocities were extracted for each position and the following overall statistics were computed for each season:

- the means and standard deviations for each of the observed current speed, the model current speed, the magnitude of the vector velocity difference between the observed and model velocities, and the difference angle between the observed and model velocities; and

- a difference ratio defined as the ratio of the sum of the squared magnitudes of the vector velocity differences to the sum of the squared magnitudes of the observed velocities, with lower values indicating better agreement and values exceeding 1 indicating poor agreement.

The observed seasonal-mean currents at representative positions in winter and summer (Fig. 4) illustrate the overall circulation pattern. There is a general equatorward and cyclonic flow tendency (with the coast to the right looking downstream) in both winter and summer, with strongest magnitudes near the surface and in the northwest gulf, in Cabot Strait, and on the inner 
Scotian shelf. These distributions also indicate the limited data coverage and the generally weaker and more spatially variable flows in most other areas.

\section{Hydrographic structure}

The horizontal, vertical, and seasonal variations in temperature and salinity are illustrated by the surface and bottom distributions of the reconstructed winter and summer fields (Fig. 5) and vertical distributions on a cross-shelf (Burin) and two cross-channel (Gaspé and Cabot Strait) sections (Fig. 6). The surface temperature has a large seasonal change associated with air-sea fluxes, with magnitudes typically $10^{\circ}-15^{\circ} \mathrm{C}$ but larger in some areas, and largest horizontal changes at the shelf water-slope water boundary, and on the SNS and in the northern gulf in summer. In contrast, the bottom temperature has little seasonal change except in shallow areas and exhibits distinct spatial variations associated with water depth variations in combination with the basic vertical temperature structure (McLellan 1954).

The surface salinity fields for winter and summer (Fig. 5) show broadscale similarity, with low-salinity sources and/or advective influences apparent in the LSLE and southwestern gulf and along the Nova Scotia coast, and values generally increasing eastward in the gulf and offshore across the shelf and slope. However, there is a significant seasonal variation with a range typically near one unit on the shelf and two units in the gulf, associated primarily with the spring peak in freshwater discharge from the St. Lawrence and other rivers (e.g., Sutcliffe et al. 1976). Similar to bottom temperature, there is limited seasonal but distinct spatial variability in bottom salinity associated with the water depth variations, including clear evidence for penetration at depth of high-salinity slope water into the upper reaches of the gulf via the Laurentian Channel.

In the following two subsections we discuss the winter and summer hydrographic structure in more detail, focusing on implications for the circulation.

\section{a. Winter (January-February)}

In winter (Fig. 5), cool surface water with limited spatial variability covers the entire gulf and shelf region, with coldest water (below $0^{\circ} \mathrm{C}$ ) in the gulf [which usually becomes ice covered in January (Koutitonsky and Bugden 1991)]. Overall, the surface temperature pattern is consistent with equatorward flow plus enhanced cooling in the gulf, including a weak cross-shelf increase on the ESS suggesting outflow of subzero surface water through Cabot Strait. Bottom temperature in winter ranges from below $0^{\circ} \mathrm{C}$ in surface-cooled shallow areas on the SNS, in the SBI, and over the Magdalen Shallows, to about $8^{\circ} \mathrm{C}$ in Emerald Basin due to the onshelf penetration of slope water at depth through the Scotian Gulf (west of Sable Island Bank). A general feature of the spatial structure is relatively warm bottom water in the deep channels and basins (compared to banks) associated with the slope-derived lower layer on the shelf and in the gulf (Loder et al. 1997) and in a band along the upper slope (e.g., Gatien 1976).

The winter surface salinity field (Fig. 5) shows the basic pattern of increases toward the east and offshore, but with higher overall values and weaker gradients than in the other three seasons (Bugden 1981). Relatively fresh water from the St. Lawrence and other rivers extends along the coast around the Gaspé Peninsula, the southwestern Gulf, and northeast Nova Scotia onto the inner Scotian shelf. The relatively high salinity near the SBI indicates Labrador shelf water entering the gulf through the strait, consistent with the peak winter inflow found by Petrie et al. (1988). The winter bottom salinity field strongly reflects the topographic regime and the vertical salinity structure of a monotonic increase with depth below the surface. The major pathways for the penetration of slope water (and associated properties such as nutrients) into the gulf-shelf system at depth are apparent; namely, through the Laurentian, Esquiman, and Anticosti Channels into the Gulf of St. Lawrence, through side channels onto the SNS, through the Scotian gulf, and to a lesser extent, the Gully (east of Sable Island) onto the Scotian shelf. These inflows suggest a two-layer "estuarine" aspect to the overall gulf-shelf system, which can have significant influences on the interannual variability of water properties at all depths (Bugden 1991; Petrie and Drinkwater 1993).

The winter density structure (Fig. 6) for the two Laurentian Channel sections shows moderate stratification, which is primarily associated with the salinity structure, with differences of about $2 \sigma_{t}$ units over the upper 200 $\mathrm{m}$ and little stratification below. On the southern side of the Gaspé section, the sloping isopycnals of the Gaspé Current are clearly apparent (e.g., Tang 1980), and there is an indication of a broader outflow on Cabot Strait's western side. The winter density distribution on the shelf (Fig. 5; also see Fig. 3 of Han et al. 1997) indicates generally weak stratification, with little stratification in the upper $50 \mathrm{~m}$.

\section{b. Summer (July-August)}

The summer surface temperature field (Fig. 5) contrasts the winter field in both average value and spatial pattern. The largest spatial variations now occur in the LSLE, in Jacques Cartier Strait along the north shore of the gulf, and over the SNS. The coolest surface temperatures in the entire domain occur in Jacques Cartier Strait, associated with the wind-forced upwelling of cold water from intermediate depths (Koutitonsky and Bugden 1991; Bourque and Kelley 1995). In contrast, spatial variations on the ESS are generally weaker than in winter, with less evidence of Cabot Strait outflow but some indication of coastal upwelling (Petrie et al. 1987; also see Loder et al. 1997). The summer bottom temperature field is similar to that in 

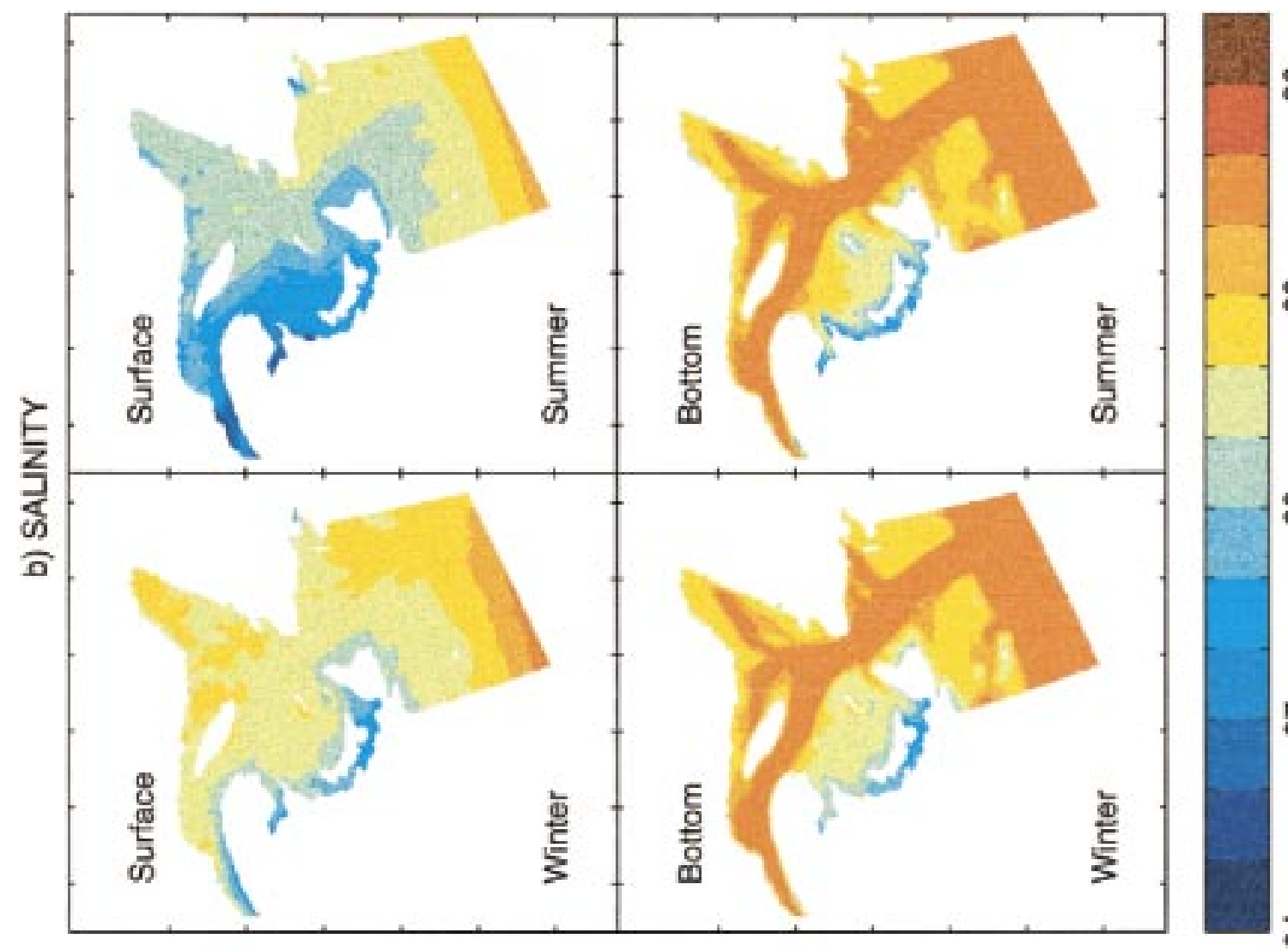

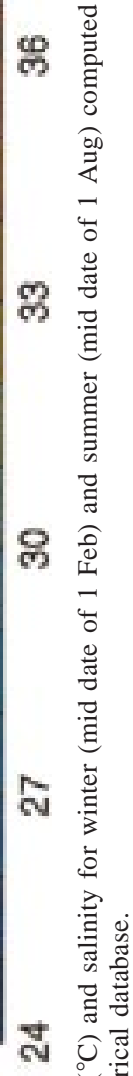
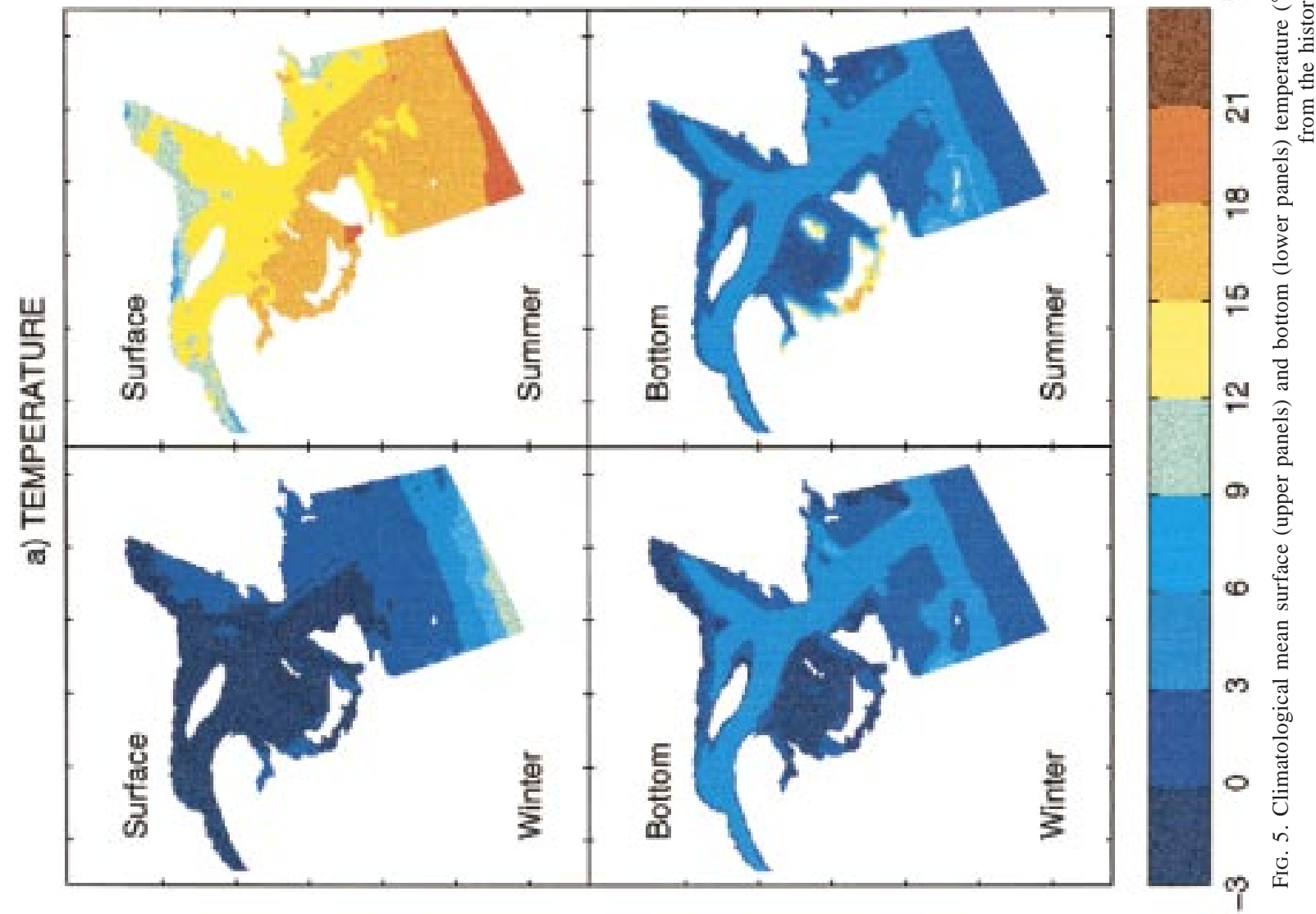

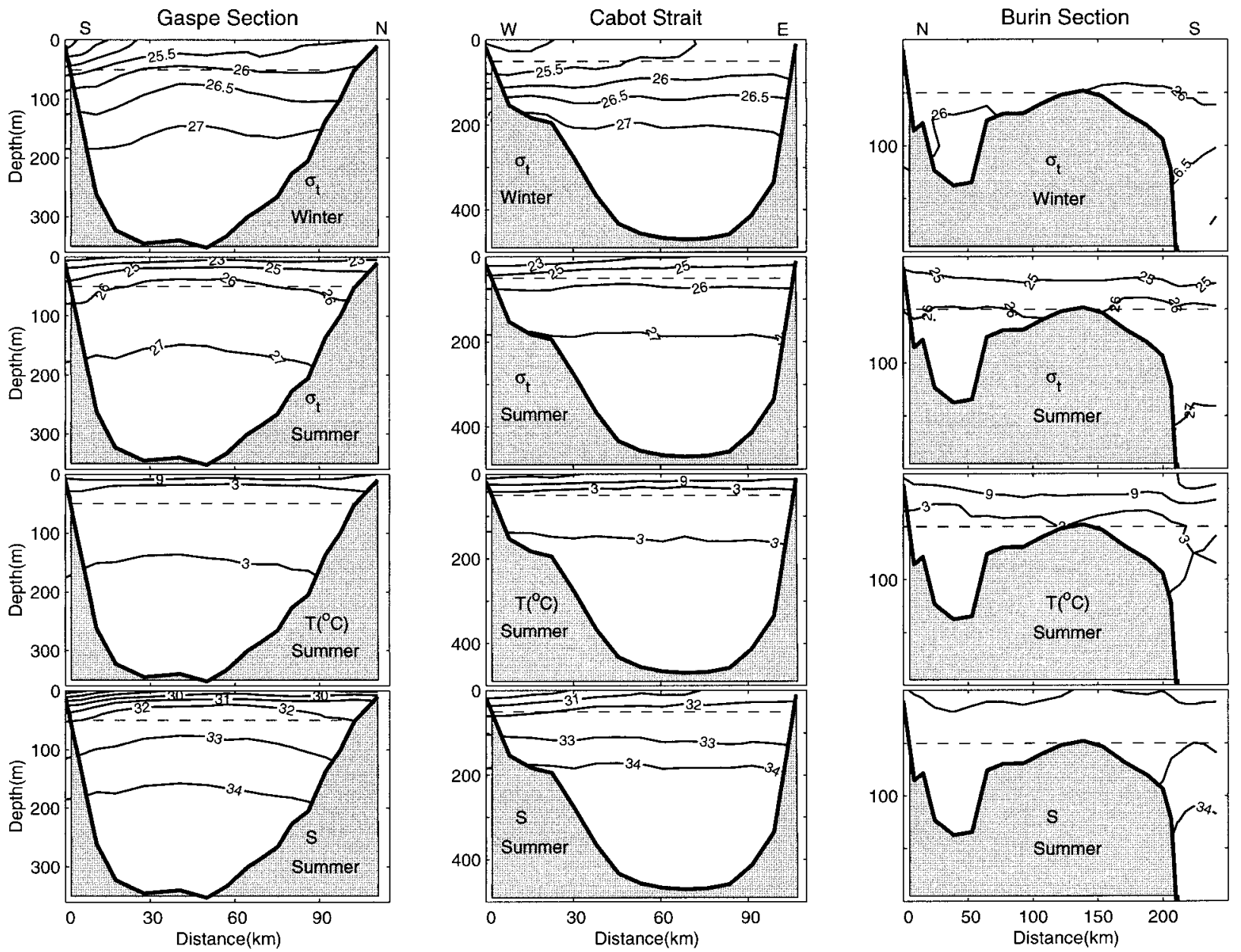

Fig. 6. Vertical distribution of density ( $\sigma_{t}$ units) on the Gaspé, Cabot Strait, and Burin sections for winter (top row) and summer (second row). The contour interval for winter is $0.5 \sigma_{t}$ units, and for summer $1.0 \sigma_{t}$ units for values of 25 and higher, and $2 \sigma_{t}$ units for lower values. Also shown are temperature (third row, with contours at $6^{\circ} \mathrm{C}$ intervals) and salinity (bottom row, with contours at 1-psu intervals) in summer. The dashed line is the 50-m level.

winter over most of the domain, with the largest seasonal changes occurring in shallow areas such as Northumberland Strait, Sable Island Bank, and the Magdalen Shallows where the seafloor protrudes into the seasonally heated surface layer.

The summer surface salinity field (Fig. 5) clearly shows the influences of the annual cycle of river discharge, with the relatively fresh water from the spring discharge peak spreading offshore in the gulf and onto the ESS. The spatial pattern is qualitatively consistent with the known seaward flow in the western gulf, and with the greatest freshwater discharge being into the LSLE with additional significant discharge from the Miramichi River (south of Gaspé) and distributed along the Quebec north shore (Koutitonsky and Bugden 1991). There is a well-defined plume extending along the western sides of Cabot Strait and the Laurentian Channel with a bifurcation onto the inner Scotian shelf, reflecting the passage of the annual salinity minimum through
Cabot Strait in late summer (September; Sutcliffe et al. 1976). In contrast, the summer bottom salinity field shows little change from the winter field and strongly reflects the topographic regime.

In summer there is strong stratification in the gulf associated with both the warming and freshening of the surface waters. Vertical density differences over the upper $50 \mathrm{~m}$ are about $4 \sigma_{t}$ units on the Gaspé section and $3 \sigma_{t}$ units on the Cabot Strait section, with sloping isopycnals indicating surface-intensified seaward geostrophic flow across these sections (Fig. 6). On the ESS there is also strong summer stratification associated with surface warming and advective freshening, with vertical density differences of about $3 \sigma_{t}$ over the upper $50 \mathrm{~m}$ (see Banquereau section in Fig. 3 of Han et al. 1997). In contrast, summer stratification is weaker on the SNS (see Burin section in Fig. 6), with vertical differences of about $2 \sigma_{t}$ units due primarily to surface heating, and no clear indication of baroclinic flow. 


\section{Circulation fields}

We start with some representative barotropic model solutions for upstream boundary inflows and then describe the total composite seasonal solutions with baroclinic, wind, and boundary forcing. The streamfunction for the depth-integrated transport is used to present the horizontal circulation patterns, complemented by the near-surface velocity fields for the winter and summer composite solutions. The normal velocity distribution on the Gaspé, Cabot Strait, and Banquereau sections, and the vertical profiles of current at selected observational sites show the 3D structure in particular areas of interest. Comparison with observational transport estimates and the moored current measurements is used to evaluate the flow fields.

We focus on the circulation fields in the gulf and over the shelf and upper continental slope since the reliability of the baroclinic solutions in the deep ocean is limited by sparse density data.

\section{a. Barotropic inflows on upstream boundaries}

The specification of upstream boundary conditions is an important general problem in regional shelf circulation modeling. It is of particular importance to the present study region in view of the observed flows through the SBI (Petrie et al. 1988) and of the Labrador Current's predominant influence on the overall northwestern Atlantic shelf circulation (e.g., Greenberg and Petrie 1988; Loder et al. 1998). In this section we examine the barotropic pathways for SBI and SNS inflows, extending Loder et al.'s (1997) shelf investigation to the coupled gulf-shelf system.

The pathways for SBI inflow are illustrated by the transport streamfunction field (Fig. 7b, Table 1) for a solution forced only by a linear elevation slope (southto-north setup of $0.1 \mathrm{~m}$ ) across the SBI, providing a uniform velocity and total transport of $0.5 \mathrm{~Sv}$ through the SBI. The flow spreads broadly across the northern gulf with branches both west and east of Anticosti Island, and converges in the southern gulf to provide an approximately uniform outflow through Cabot Strait, which converges farther into a narrow flow along the edge of the ESS. Thus, barotropic inflow through the SBI has relatively widespread influences on the circulation in the gulf and Cabot Strait regions, but more localized influences on the shelf confined to Laurentian Channel and the ESS edge. An alternative SBI inflow solution with a uniform 0.1-m setup on the SBI (Table 1) has a similar overall transport pattern, indicating that this pattern is not very sensitive to the details of the inflow.
Following Loder et al. (1997), the pathways for SNS inflow are examined using solutions with linear elevation setups (and hence uniform velocities) specified on two different SNS boundary segments (Fig. 1): 1) the inner SNS-I portion $(74 \mathrm{~km})$ representing the probable location of the inshore Labrador Current and 2) the shelf-break (SNS-SB) portion $(150 \mathrm{~m} \leq h \leq 940 \mathrm{~m})$ representing the probable location of the offshore Labrador Current. A nominal sea level difference of $0.1 \mathrm{~m}$ is used across each segment, providing transports of approximately 1 and $3 \mathrm{~Sv}$ across the SNS-I and SNSSB segments.

The transport patterns associated with these SNS boundary forcings are shown in Figs. 7c and 7d, with values on particular sections given in Table 1 . About half of the SNS-I inflow moves along the coast to Cabot Strait, with much of this inshore portion then meandering into the Gulf of St. Lawrence to form a topographically steered cyclonic circulation over the deep channels to the south and east of Anticosti Island. All of this flow exits the gulf through Cabot Strait with none reaching the SBI. There is also an offshore pathway for the SNS-I inflow, involving flows around and over St. Pierre Bank, which merge with the inshore component on the western side of Laurentian Channel and then move along the ESS edge. In contrast, only about one-sixth of the SNS-SB inflow meanders into the Gulf of St. Lawrence (with a similar pattern and fate as the SNS-I inflow) with another one-sixth of the SNS-SB inflow meandering into the outer Laurentian Channel before moving along the ESS edge, and the remaining two-thirds moving along the shelf edge. Thus, the influences of barotropic SNS inflows are primarily confined to the SNS, Laurentian Channel, deep areas of the southern gulf, and the ESS edge.

To illustrate the combined influences of the SNS-I and SNS-SB inflows, and for use in the seasonal composite solutions (sections $4 \mathrm{~b}-\mathrm{d}$ ), we use linear superposition to obtain a composite SNS barotropic inflow solution (Fig. 7e, Table 1) with a flow into the gulf through eastern Cabot Strait of about 0.5 Sv receiving equal contributions from the two inflows. The transports across the SNS-I and SNS-SB boundaries are 0.5 and $1.8 \mathrm{~Sv}$, with a net elevation change of $0.12 \mathrm{~m}$. In this case, about one-quarter of the total SNS inflow meanders into the gulf, another one-quarter meanders into the outer Laurentian Channel, and the other half remains along the shelf break and upper slope. The shelf flow pattern in this case is qualitatively similar to that in the composite barotropic case constructed by Loder et al. (1997, their Fig. 8a) for the combination of SNS and Cabot Strait inflows, with the exceptions that the flow

FIG. 7. Transport streamfunction for barotropic model solutions for (b) SBI inflow of $0.5 \mathrm{~Sv}$, (c) inner SNS inflow of $1 \mathrm{~Sv}$, (d) shelf-break SNS inflow of $3 \mathrm{~Sv}$, (e) a composite case comprising $0.5 \mathrm{~Sv}$ of inner SNS inflow and $1.8 \mathrm{~Sv}$ of shelf-break SNS inflow, and (f) the composite case with bottom friction and viscosity coefficients increased by a factor of 4 . The base-case friction and viscosity coefficients derived 

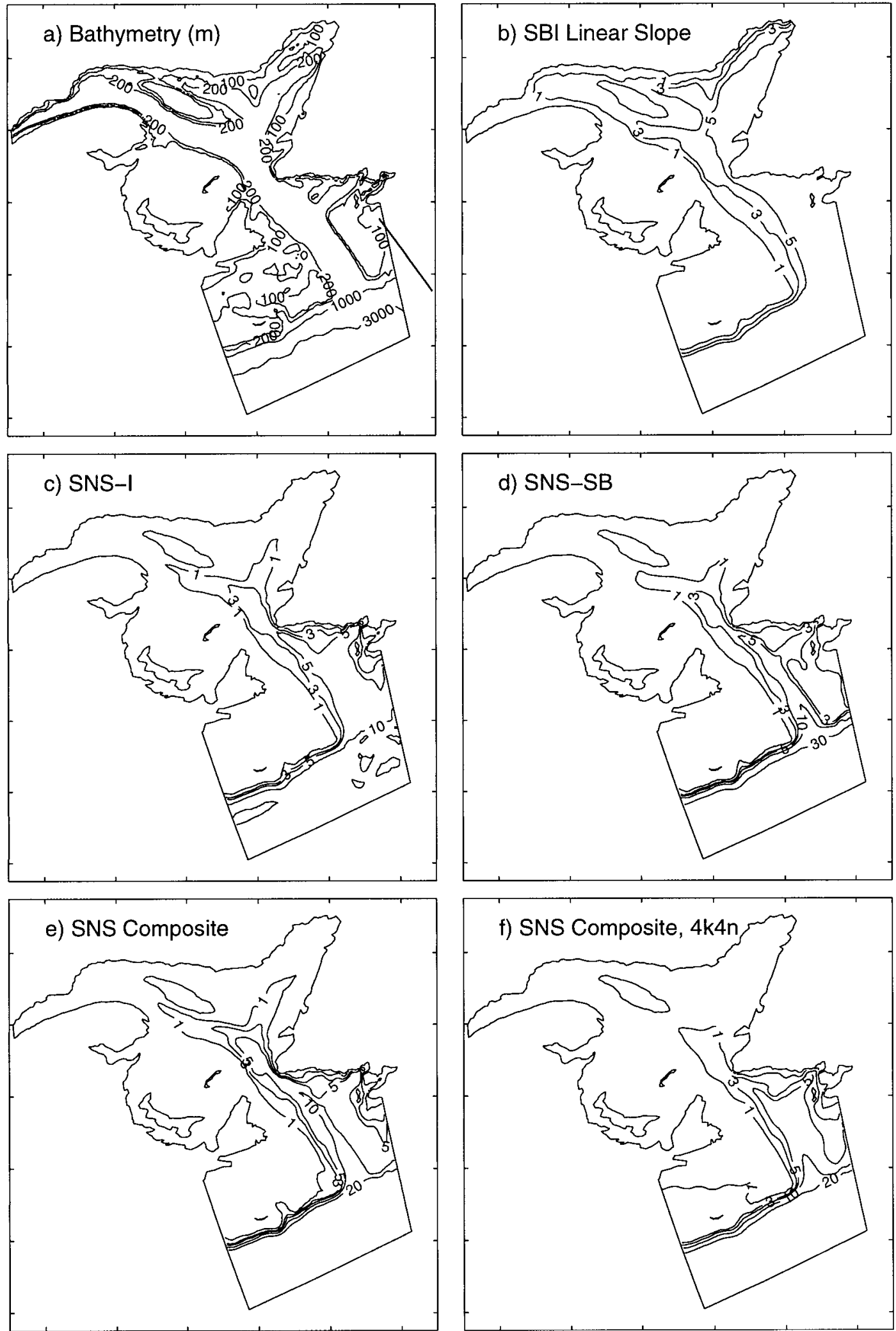

FIG. 7. (Continued) from the nonlinear $M_{2}$ tidal solution are used in (b)-(e). The streamlines are labeled in units of deci-Sv $\left(10^{5} \mathrm{~m}^{3} \mathrm{~s}^{-1}\right)$, with a value of zero specified on the Labrador [in (b)] or Newfoundland [in (c)-(f)] coast, and low values on the right looking downstream. The regional bathymetry is shown in (a) using the 100-, 200-, 1000-, and 3000-m isobaths. The thicker line crossing the SNS boundary in (a) shows the location of the TOPEX/Poseidon track used in Fig. 9. 
TABLE 1. Transports (in Sv) across key sections in the barotropic boundary-inflow cases. Positive transports are southeastward, or seaward in Cabot Strait. CS-W and CS-E stand for western and eastern Cabot Strait divided at the deepest location. See Fig. 1 for location of the other sections.

\begin{tabular}{lcllcrrrr}
\hline \hline Inflow case & Fig & SBI & SNS-I & SNS-SB & CS-W & CS-E & L1 & L2 \\
\hline SBI: Slope & $7 \mathrm{~b}$ & 0.5 & 0.0 & 0.0 & 0.30 & 0.20 & -0.01 & 0.47 \\
SBI: Uniform & & 0.52 & 0.0 & 0.0 & 0.34 & 0.18 & -0.01 & 0.52 \\
SNS: Inner & $7 \mathrm{c}$ & 0.0 & 0.92 & -0.01 & 0.45 & -0.45 & 0.02 & 0.62 \\
SNS: SB & $7 \mathrm{~d}$ & 0.0 & 0.03 & 2.60 & 0.41 & -0.41 & 0.03 & 1.53 \\
SNS: Comp & $7 \mathrm{e}$ & 0.0 & 0.53 & 1.80 & 0.55 & -0.55 & -0.02 & 1.86 \\
SNS: 4k4n & $7 \mathrm{f}$ & 0.0 & 0.55 & 2.00 & 0.30 & -0.30 & 0.15 & 1.39 \\
\hline
\end{tabular}

out of the gulf through Cabot Strait and Laurentian Channel is broader here and there is less flow onto the inner ESS because the Cabot Strait flow is in deeper water. These differences arise from the present coupled gulf-shelf model allowing inflow-outflow interactions in Cabot Strait consistent with the gulf's geometry.

The structure of these barotropic inflow solutions is determined by the relation of the specified boundary inflows to geostrophic ( $f / h$ where $f$ is the Coriolis parameter) contours and the strength of bottom friction (e.g., Csanady 1978). The influence of stronger friction (e.g., associated with other tidal constituents or storm influences) is illustrated by a sensitivity solution for the composite inflow case with the bottom friction coefficient and vertical eddy viscosity values increased by a factor of 4 (Fig. 7f, Table 1). There is reduced meandering into the gulf and Laurentian Channel associated with the increased offshore diffusion of the coastally trapped flow on the SNS. In contrast, the increased cross-shelf diffusion on the ESS results in both onshelf and offshore spreading of the shelf-break flow. Nonetheless, the primary areas of influences for SNS barotropic inflow remain the SNS, Laurentian Channel, deep southern gulf, and ESS edge.

A composite summer solution with baroclinic, wind, and SBI barotropic inflow forcing, but no barotropic inflow across the SNS boundary, underestimates the ob-

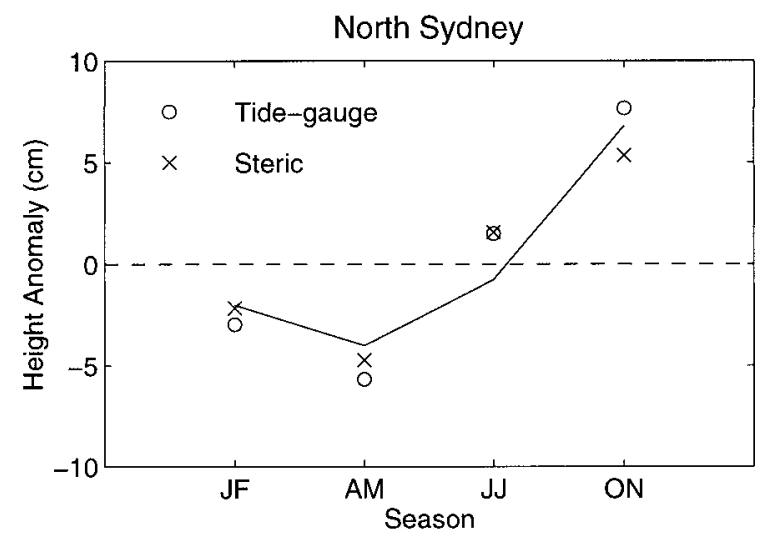

FIG. 8. Seasonal sea level anomalies at North Sydney, NS. Crosses are steric height estimates obtained from the 3D density fields, and open circles are observational estimates from tide-gauge data adjusted for inverse barometric effects. The solid line is from the model solutions with baroclinic, wind, and SBI and SNS inflow forcing. served current speeds at sites on the eastern side of Cabot Strait and along the ESS edge and has transports in and out of Cabot Strait that are less than observational estimates by about $0.5 \mathrm{~Sv}$ (see next two sections). Considering the barotropic pathways identified above, these discrepancies point to the occurrence of significant barotropic inflow across the SNS boundary. To investigate this further, we compare steric estimates of sea level variations associated with the present seasonal density fields and observed sea level variations in the ESS-SNS region. The seasonal anomalies (relative to the annual mean) of steric sea level at North Sydney, Nova Scotia, are in approximate agreement with the seasonal changes recorded by a tide gauge during 1971-95 and adjusted for the local inverse barometric effect (Fig. 8). This suggests that any barotropic flow on the western side of Cabot Strait has a limited seasonal variation. Correspondingly, the seasonal steric height anomalies along the shelf and upper-slope portions of the SNS boundary (Fig. 9) have similar magnitudes and spatial structure to observed sea level anomalies from nearby TOPEX/ Poseidon altimetry data (Han and Smith 1997), also suggesting a limited seasonal variation in any barotropic inflow over the shelf. Consequently, as a first approximation to additional barotropic inflow across the SNS boundary, we include the same composite barotropic SNS inflow (Fig. 7e) in the total composite solutions for the four different seasons (next three sections). The seasonal changes of the model elevations at North Sydney for the four seasons (Fig. 8) agree approximately with the steric estimates and the tide gauge data, further supporting this approximation.

\section{b. Summer (July-August)}

We first present the composite solution for summer, which has the best information for setting the SBI and SNS inflows, the largest monthly currents dataset, and the best overall agreement between the model and observed currents.

In the Gulf of St. Lawrence the circulation has a broadscale cyclonic tendency that is intensified in local deep areas (Fig. 10c). There is a weak SBI inflow of $0.1 \mathrm{~Sv}$ from the Labrador shelf, consistent with the observational estimate of $0.13 \mathrm{~Sv}$ (Table 2: note that the SBI surface elevation was tuned to the measured near- 

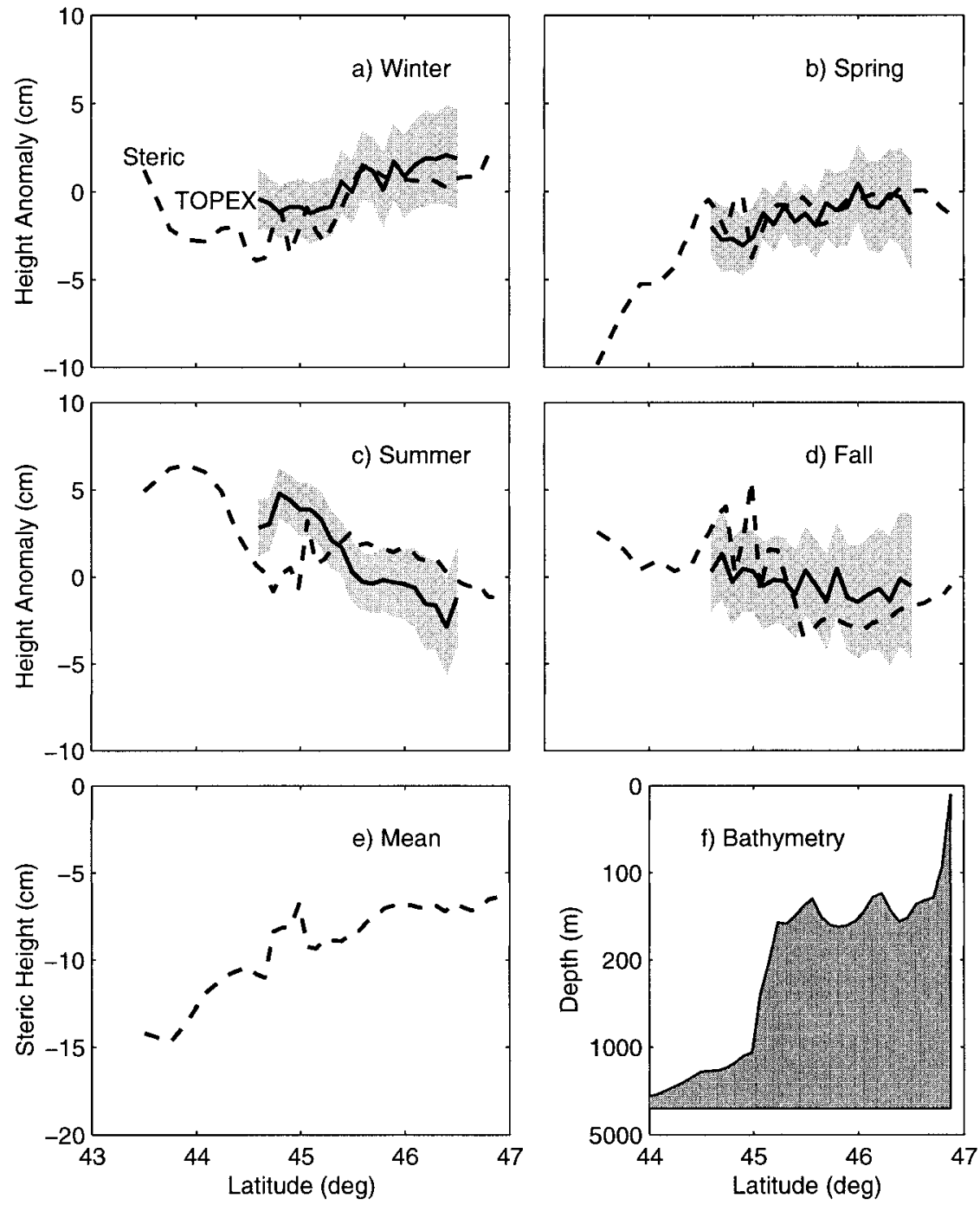

FIG. 9. Seasonal sea level anomalies along the SNS boundary for (a) winter, (b) spring, (c) summer, and (d) fall. Dashed lines are steric height estimates computed from the seasonal density field along the boundary, and solid lines are TOPEX/Poseidon altimetry data for 1992-96 with the gray shading indicating the standard error (Han and Smith 1997). The variations in annualmean steric height and bottom topography along the boundary are shown in (e) and (f). See Fig. 7a for the TOPEX/Poseidon track location.

surface currents rather than the total transport; see section 2c). The SBI inflow moves along the gulf's north shore and reinforces an intense cyclonic gyre in the northwest gulf (Figs. 11b, 12a) that has a peak transport of about 1.1 Sv. The gyre's southern limb is the Gaspé Current, traditionally recognized as a baroclinic coastal jet driven by the runoff from the LSLE and reinforced by transverse currents from the gulf's north shore (Tang 1980), which has a peak near-surface speed of $50 \mathrm{~cm}$ $\mathrm{s}^{-1}$. The solution indicates that a substantial fraction of the Gaspé Current's transport recirculates in the northwest gulf (for which there is some observational support; Fig. 4), but considering the surface salinity distribution (Fig. 5), it seems likely that the seaward throughflow is underestimated because of a suspect small-scale feature (disrupting the $0.3-$ Sv contour in Fig. 10c). The seaward flow bifurcates off the eastern tip of the Gaspé Peninsula, with one branch moving along the southern Magdalen Shallows and the north coast of Prince Edward Island and the other branch continuing along the southern side of Laurentian Channel. The two branches then reunite and flow out of the gulf on the western side of Cabot Strait with a peak near-surface speed of $20 \mathrm{~cm} \mathrm{~s}^{-1}$, while the primary flow into the gulf is located on the strait's eastern end with a peak speed of $15 \mathrm{~cm} \mathrm{~s}^{-1}$ and limited vertical structure (Fig. 12a). The outflowing $(0.8 \mathrm{~Sv})$ and inflowing $(0.7 \mathrm{~Sv})$ transport magnitudes through the strait are in approximate agree- 

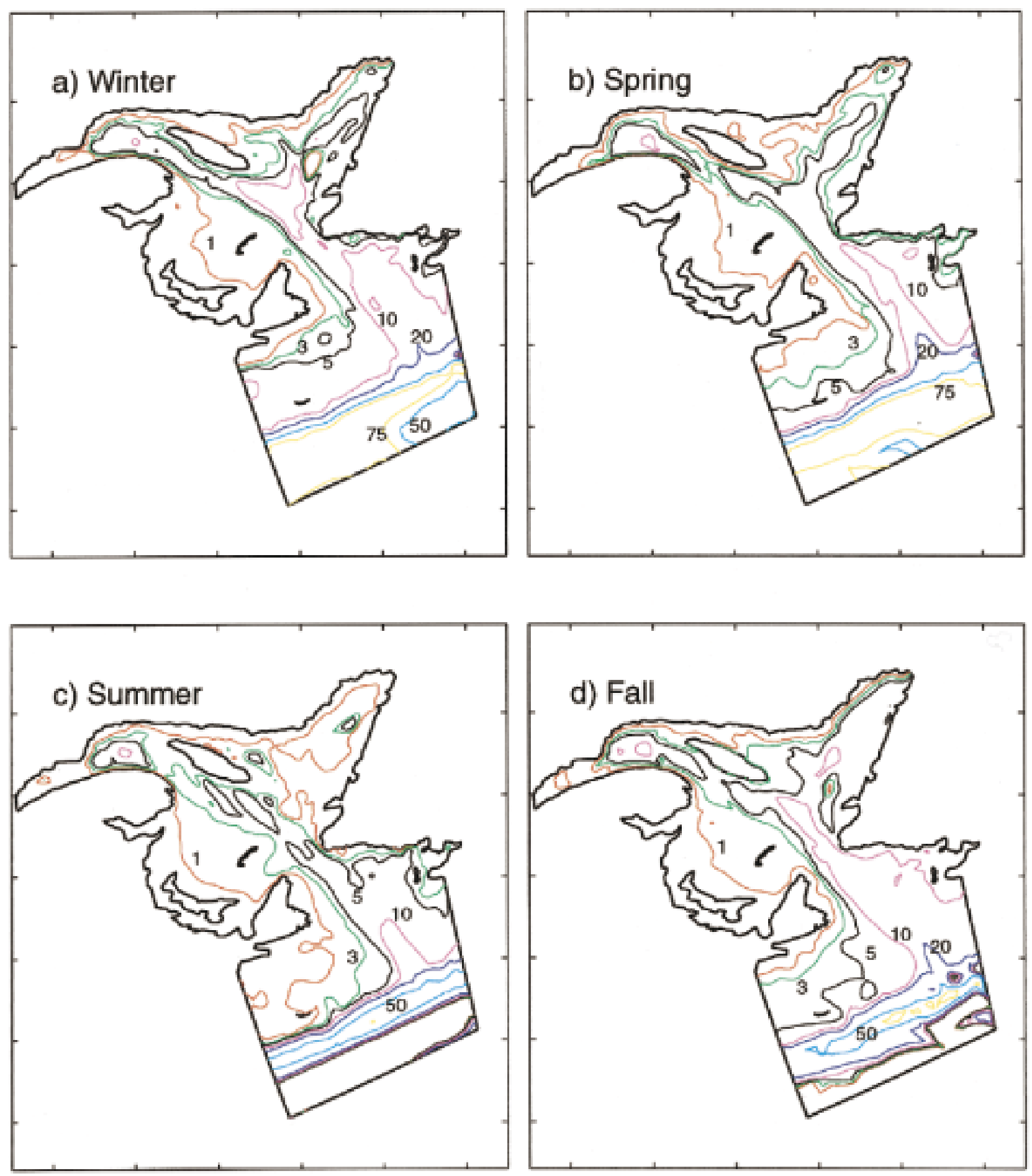

FIG. 10. Transport streamfunction in units of deci-Sv $\left(10^{5} \mathrm{~m}^{3} \mathrm{~s}^{-1}\right)$ for (a) winter, (b) spring, (c) summer, and (d) fall from the composite base model solutions. The forcing are baroclinic pressure gradients, wind stresses, and steric boundary conditions, except for additional flow components on the SBI, SNS, and ESS boundaries (as discussed in the text). The streamfunction value is zero along the Nova Scotia coast and the south and north shores of the gulf, with low values on the right looking downstream; that is, the flow is cyclonic around local streamfunction maxima and anticyclonic around local minima. The streamfunction values are 3,2, 1, and 5 deci-Sv along the Newfoundland coast. 
TABLE 2. Transports (in Sv) across key sections in the base composite model solutions with baroclinic, wind, and boundary forcing. Positive transports are southwestward, or seaward in Cabot Strait. Observational estimates from Anderson and Smith (1989), Trites (1972) and Petrie et al. (1988) are included in parentheses. The model solutions without additional SNS barotropic inflow have transports reduced by $0.5 \mathrm{~Sv}$ on CS-W and CS-E (western and eastern Cabot Strait divided at the location with the maximum transport streamfunction value). See Fig. 1 for location of the other sections.

\begin{tabular}{lcccccccc}
\hline \hline Period & Fig. & SBI & SNS-I & SNS-SB & CS-W & CS-E & L1 & L2 \\
\hline Jan-Feb & 10a & $0.3(0.3)$ & 0.7 & 1.1 & 1.0 & -0.7 & $0.9(0.7)$ & 3.1 \\
Apr-May & 10b & $0.2(0.3)$ & 0.6 & 1.1 & 1.0 & -0.8 & 0.2 & 3.1 \\
Jul-Aug & 10c & $0.1(0.13)$ & 0.5 & 2.4 & $0.8(0.84)$ & $-0.7(-0.75)$ & 0.1 & 2.2 \\
Oct-Nov & 10d & 0.5 & 0.7 & 1.5 & 1.3 & -0.8 & 0.3 & 2.6 \\
\hline
\end{tabular}

ment with observational estimates by Trites (1972) ( 0.84 and $0.75 \mathrm{~Sv}$, respectively), in contrast to the values of 0.3 and $0.2 \mathrm{~Sv}$ for the model solution without the additional SNS inflows. The net transport of about $0.1 \mathrm{~Sv}$ out of the gulf through Cabot Strait is larger than El Sabh's (1977) salt balance estimate of $0.01 \mathrm{~Sv}$.

Most of the Cabot Strait outflow continues along the western edge of the Laurentian Channel to the outer ESS, but there are weak transports of 0.1 and $0.2 \mathrm{~Sv}$, respectively, onto the inner and middle ESS (Figs. 10c and 11b). All of the SNS-I inflow (0.5 Sv, Table 2) flows along the Newfoundland coast and enters the gulf through the eastern side of Cabot Strait, while the SNSSB inflow $(2.4 \mathrm{~Sv})$ moves southwestward along the ESS edge and slope, with a small portion meandering into the outer Laurentian Channel. The circulation on the Banquereau section (Fig. 12c) is dominated by the major southwestward artery near the shelf edge, with weaker currents on the shelf. The flows over the upper slope in this and the other seasons are qualitatively consistent with expectations for the westward-flowing northern limb of the cyclonic gyre in the Slope Water (e.g., Csanady and Hamilton 1988), but data sparsity limits the reliability of the model solutions for the middle/lower slope and deep ocean in particular. The model transport for the Nova Scotian Current on the inner Scotian shelf (Liscomb line) is at its seasonal minimum of $0.1 \mathrm{~Sv}$, consistent with the limited flow from Cabot Strait onto the ESS and (qualitatively) with Drinkwater et al.'s (1979) geostrophic estimate on the Halifax section.

Comparison of the model's near-surface currents with moored measurements in major flow features (Fig. 11b) shows good qualitative agreement, and the current comparison statistics (Table 3) indicate fair-to-good overall quantitative agreement for summer. The difference ratio value of 0.56 is the lowest of the four seasons and the average magnitudes of the model and observed currents are similar, but the average magnitudes of the vector velocity difference and difference angle indicate substantial model-observation discrepancies. The currents comparison statistics are slightly better for the composite solution without the additional SNS inflows (Table 3), but the Cabot Strait transports (Table 2) and current profile comparisons in the strait and at the ESS edge (below) suggest that the base solution is more satisfactory. The difference ratio has similar values for solutions without wind forcing, suggesting that the barotropic current component due to the summer-mean wind stress is generally small relative to the baroclinic and remotely forced barotropic components. The model current profiles at mooring sites in the major current features are in good agreement with the observed currents in direction and vertical structure, but as expected considering the limited observational datasets together with monthly and interannual variability, there are significant discrepancies in magnitude at some positions (Fig. 13b). The model solution with additional SNS inflow is in better agreement with the observed southwestward currents at site SI1 (ESS edge) and northwestward currents at CSE, compared to the model solution without the additional inflows. There is also approximate quantitative agreement in Jacques Cartier Strait (site JCS), the Gaspé Current (GP1) and in the Cabot Strait outflow (CSW), suggesting a predominant influence of baroclinicity in driving the summer circulation in the gulf.

\section{c. Winter (January-February)}

The winter solution (Figs. 10a and 11a) indicates cyclonic gulf circulation similar to that in summer, but with an enhanced strength associated, in part, with the increased SBI inflow. The net SBI inflow is now 0.3 Sv, in agreement with Petrie et al.'s (1988) observational estimate (Table 2), while the peak transport of the cyclonic gyre in the northwest gulf is again about 1.1 Sv. The Gaspé Current (Fig. 12a), though having the same peak transport as in summer, has a stronger nearshore barotropic component (in part associated with the increased SBI inflow) and a weaker baroclinic component (consistent with the reduced freshwater discharge; Fig. 5). The flow over the Magdalen Shallows is weaker than in summer, while the cyclonic circulation over the Esquiman and Anticosti Channels is intensified. In Cabot Strait the main outflow from the gulf occurs in a strong surface-intensified jet centered over the 400-m isobath with peak speed near $30 \mathrm{~cm} \mathrm{~s}^{-1}$ and a total transport of 1.0 Sv (Table 2), while the main inflow to the gulf is more barotropic and lies on the strait's eastern end with a total transport of $0.7 \mathrm{~Sv}$ (Fig. 12b). These transport magnitudes differ substantially from El Sabh's (1977) 


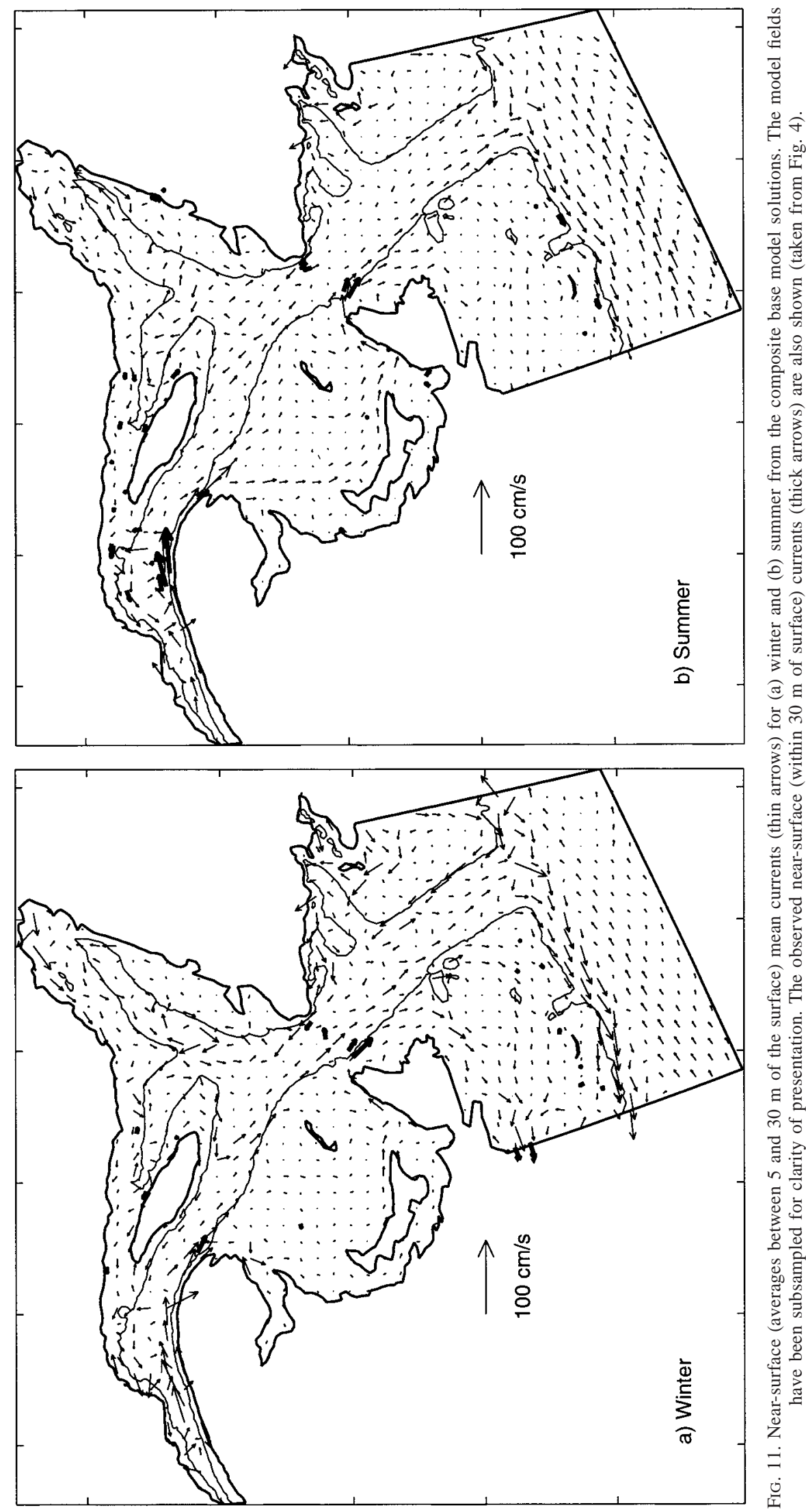



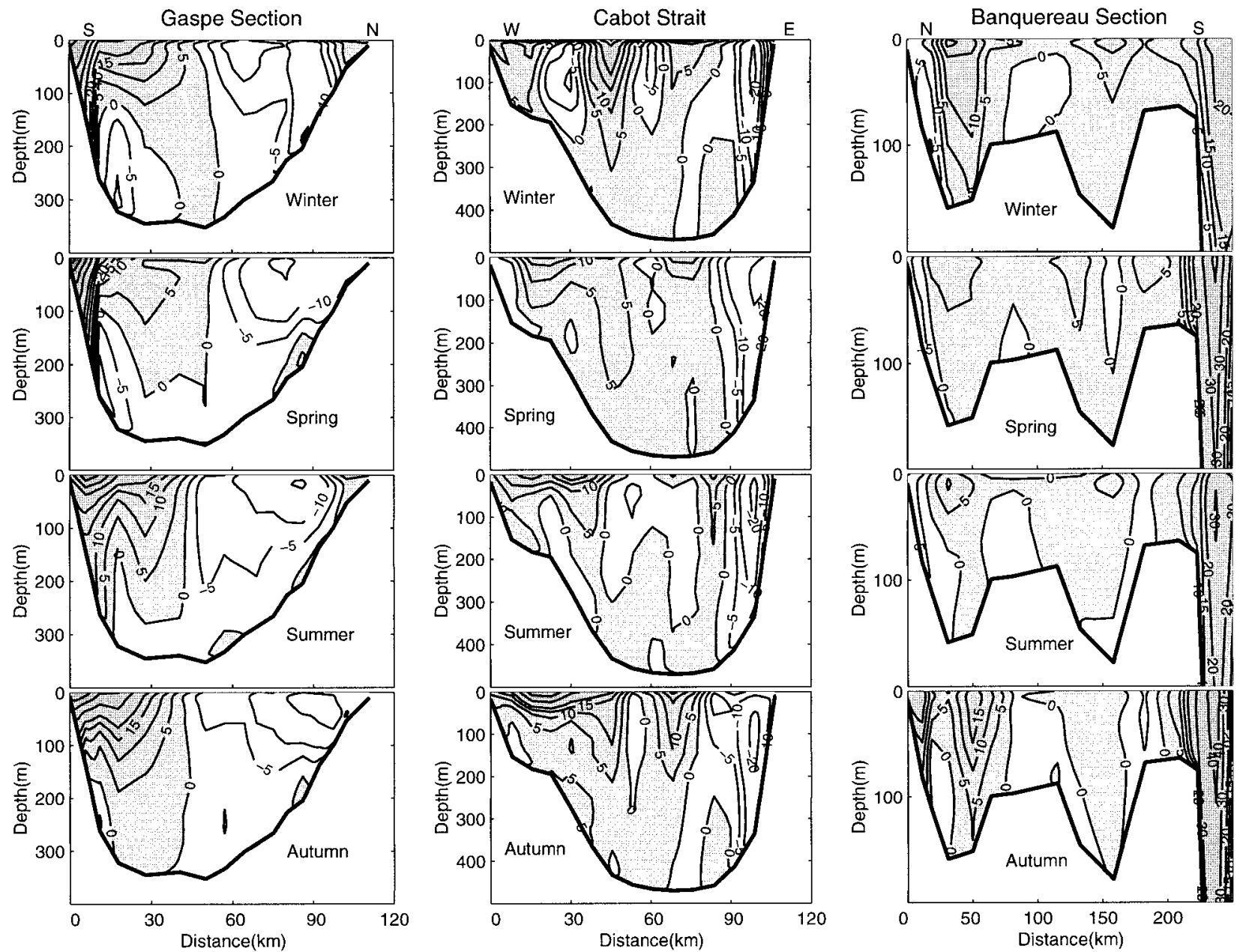

FIG. 12. Mean normal velocity on the Gaspé, Cabot Strait, and Banquereau sections for winter, spring, summer, and fall from the model solutions. The isotach interval is $5 \mathrm{~cm} \mathrm{~s}^{-1}$ for currents between -10 and $20 \mathrm{~cm} \mathrm{~s}^{-1}, 10 \mathrm{~cm} \mathrm{~s}^{-1}$ for values below $-10 \mathrm{~cm} \mathrm{~s}$, or between 20 and $50 \mathrm{~cm} \mathrm{~s}^{-1}$, and $25 \mathrm{~cm} \mathrm{~s}^{-1}$ for values above $50 \mathrm{~cm} \mathrm{~s}^{-1}$. Positive values (shaded) indicate eastward currents on the Gaspé section, seaward currents through Cabot Strait, and southeastward currents on the Banquereau section.

TABLE 3. Statistics (means and standard deviations) of the comparison between observed and modeled mean currents at mooring sites. The difference ratio (DR) is defined as the ratio of the sum of squared differences between the observed and modeled velocities to the sum of squared observed currents. The vector velocity difference (VVD) is the magnitude of the difference vector between the observed and modeled velocities. The difference angle (DA) is the magnitude of their difference in direction.

\begin{tabular}{|c|c|c|c|c|c|c|}
\hline \multirow[b]{3}{*}{ Bimonthly period } & \multirow{3}{*}{$\begin{array}{l}\text { Number } \\
\text { of obs }\end{array}$} & \multirow{2}{*}{\multicolumn{2}{|c|}{ Average speed $\left(\mathrm{cm} \mathrm{s}^{-1}\right)$}} & \multirow[b]{3}{*}{ DR } & \multicolumn{2}{|c|}{ Velocity deviations } \\
\hline & & & & & \multirow{2}{*}{$\begin{array}{c}\mathrm{VVD} \\
\left(\mathrm{cm} \mathrm{s}^{-1}\right)\end{array}$} & \multirow{2}{*}{$\begin{array}{c}\text { DA } \\
\text { (deg) }\end{array}$} \\
\hline & & Obs & Model & & & \\
\hline Jan-Feb & 76 & $7.9 \pm 7.3$ & $8.7 \pm 6.7$ & 0.75 & $7.1 \pm 6.1$ & $44 \pm 49$ \\
\hline No additional SNS inflow & & & $7.0 \pm 6.1$ & 0.79 & $7.5 \pm 5.9$ & $53 \pm 52$ \\
\hline Apr-May & 38 & $6.5 \pm 5.5$ & $7.0 \pm 5.7$ & 1.15 & $7.8 \pm 4.8$ & $68 \pm 54$ \\
\hline No additional SNS inflow & & & $4.1 \pm 5.4$ & 0.99 & $7.1 \pm 4.7$ & $73 \pm 55$ \\
\hline Jul-Aug & 144 & $9.4 \pm 11.9$ & $10.5 \pm 10.4$ & 0.56 & $8.3 \pm 7.7$ & $54 \pm 56$ \\
\hline No additional SNS inflow & & & $9.1 \pm 10.1$ & 0.52 & $7.8 \pm 7.5$ & $56 \pm 56$ \\
\hline Oct-Nov & 37 & $7.8 \pm 7.0$ & $8.6 \pm 7.6$ & 0.62 & $6.5 \pm 5.1$ & $49 \pm 54$ \\
\hline No additional SNS inflow & & & $5.7 \pm 5.4$ & 0.52 & $5.9 \pm 4.8$ & $59 \pm 54$ \\
\hline
\end{tabular}


a) Winter

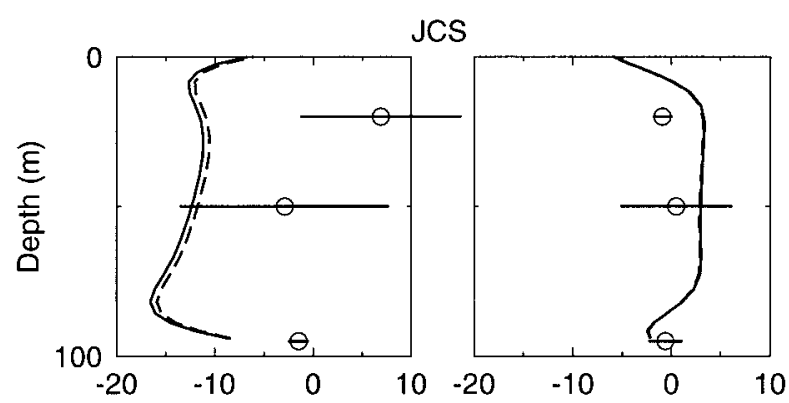

GP2
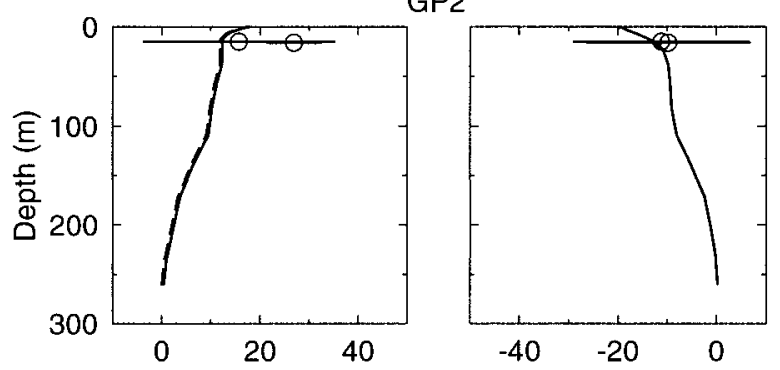

CSW

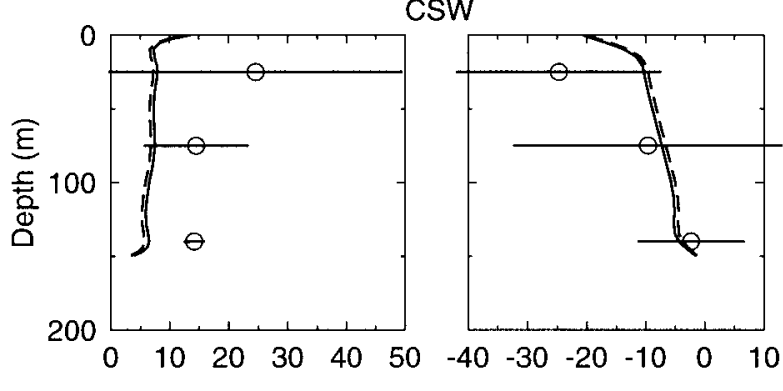

CSE

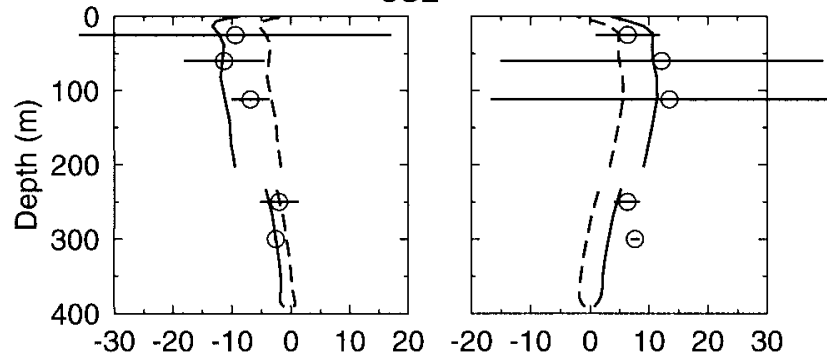

$\mathrm{SI} 2$
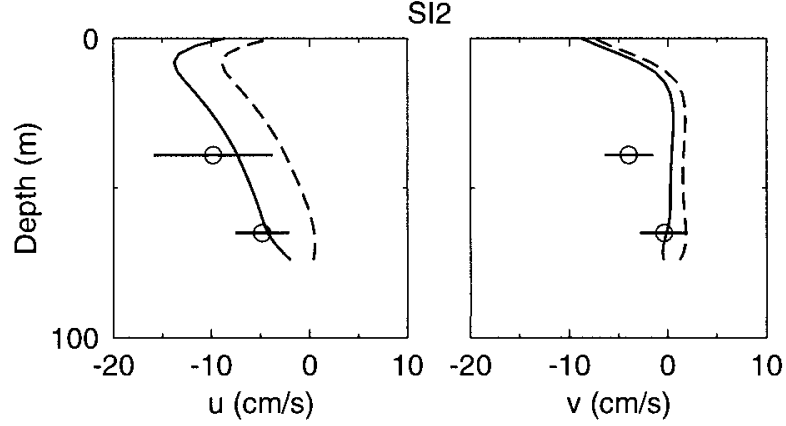

b) Summer
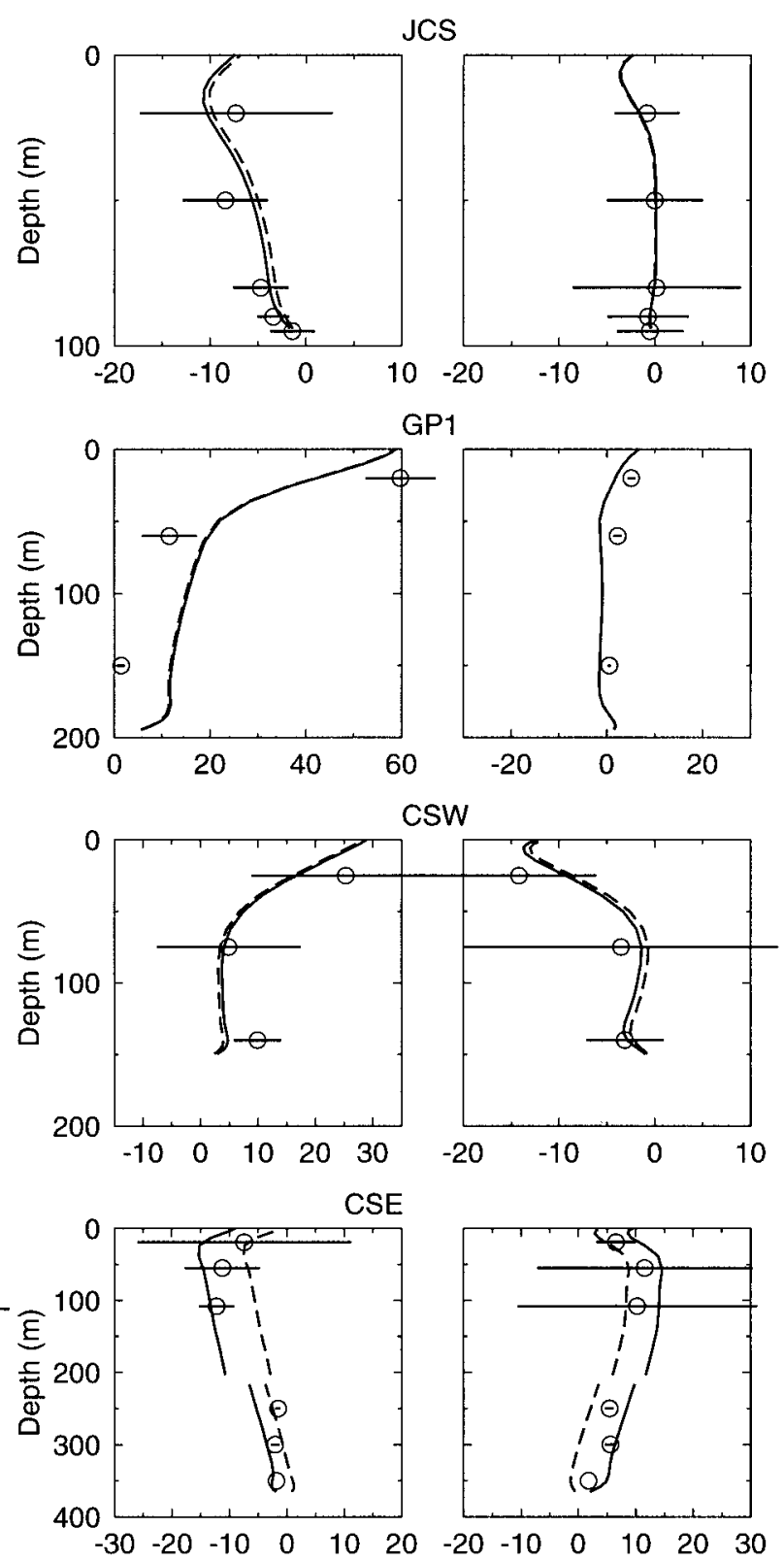

Sl1
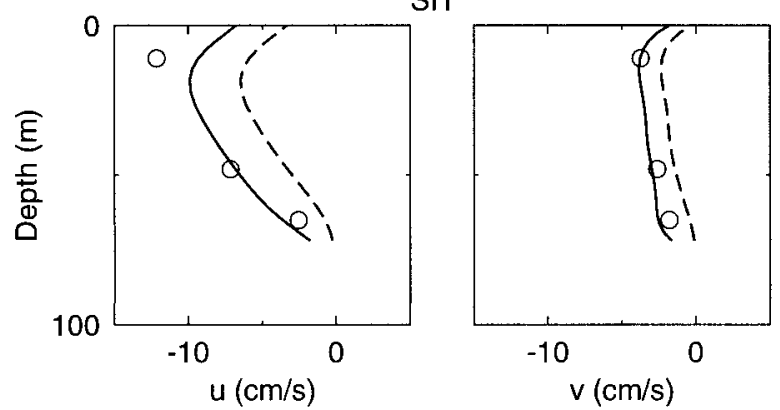

FIG. 13. Comparison of model current profiles with observed bimonthly mean currents (open circles) for (a) winter and (b) summer. Profiles from the composite base model solutions (solid curves, with additional barotropic SNS inflows) and analogous solutions without additional 
geostrophic estimates of $0.36 \mathrm{~Sv}$ due to the additional SBI and SNS inflows.

The flow on the ESS is also substantially intensified compared to that in summer, with increased flow onto the inner $(0.3 \mathrm{~Sv})$ and middle $(0.4 \mathrm{~Sv})$ shelf on the Banquereau line (Fig. 12c). Part of this intensification is associated with the increased flow through Cabot Strait but the dynamics controlling the flow onto the ESS are unclear. The Nova Scotian Current is significantly increased with a transport of $0.9 \mathrm{~Sv}$ on the downstream boundary, comparable to the moored measurement estimate of $0.7 \mathrm{~Sv}$ on the Liscomb line (Table 2; Anderson and Smith 1989), and is supplemented by an onshelf meander of part of the shelf-edge artery west of Sable Island Bank (also see Han et al. 1997). This artery is again the predominant current and transport feature on the ESS (Figs. 10a, 11a, 12c; Table 2) with a peak near-surface speed of $20 \mathrm{~cm} \mathrm{~s}^{-1}$ and a transport exceeding $3 \mathrm{~Sv}$ (out to the 1000-m isobath). The SNS-I inflow is similar to that in summer, while the SNS-SB inflow of $1.1 \mathrm{~Sv}$ is smaller than the summer value (apparently due to a suspect small-scale feature over the upper slope; Fig. 10a). However, the inflow over the SNS slope offshore of the 1000-m isobath is significantly intensified, consistent with altimetric measurements (Han et al. 1993; Han and Smith 1997) and the bimonthly solutions in Hannah et al. (1996).

The model currents are again in qualitative agreement (Fig. 11a) with, but have substantial quantitative differences (Table 3) from, the moored measurements. Overall, the current comparison statistics are similar to those for summer, with higher values (poorer agreement) of the difference ratio and lower values of the difference angle. But they suggest better agreement for the base solution than that without the additional SNS inflows. The difference ratio for a solution without the winddriven barotropic currents shows a significant increase, indicating the importance of the wind forcing in the winter season. The model current profiles in the major current features (Fig. 13a) show similarly good agreement with the observed currents as in summer for three sites (GP2, CSE, SI2), and poorer agreement for two sites (JCS, CSW). Possible candidates responsible for the large model-observation discrepancies at the JCS site are lack of historical data causing poor resolution of the hydrographic structure, poor wind estimates, and/ or ice cover effects on the observations. At the ESS edge (SI2) and eastern Cabot Strait (CSE) sites on the geostrophic contours of the SNS-SB inflows, the agreement is again improved with the inclusion of the additional barotropic SNS inflows. At the two Canadian Atlantic Storms Program (CASP) sites in the Nova Sco-
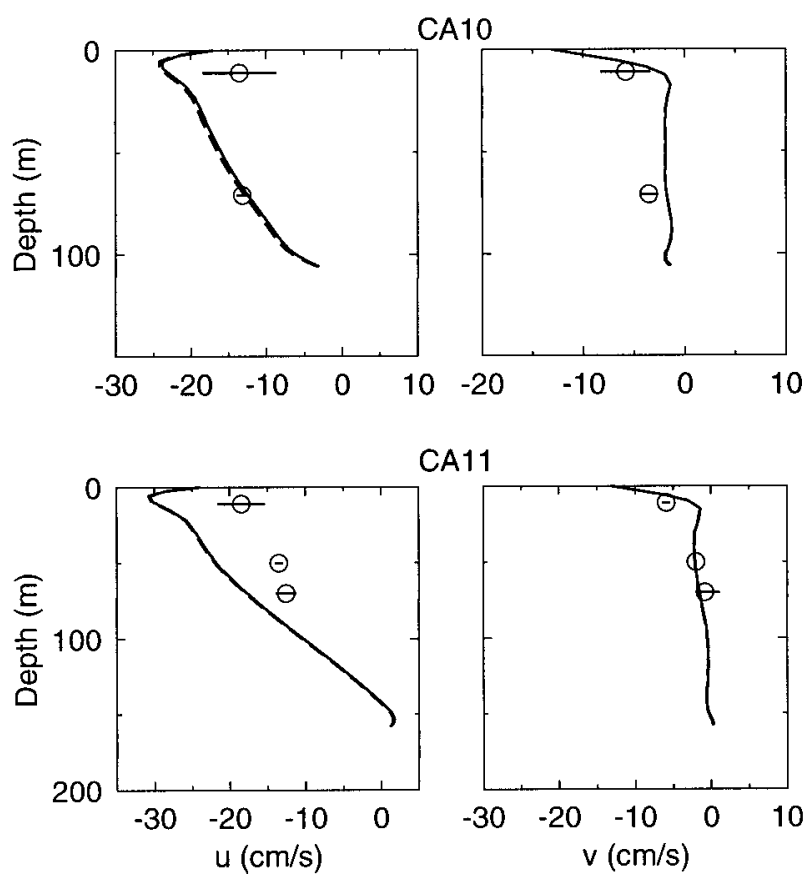

FIG. 14. Comparison of model current profiles with observed bimonthly mean currents in winter at two sites on the inner Liscomb line from the Canadian Atlantic Storms Program (CASP; Anderson and Smith 1989). Conventions as in Fig. 13.

tian Current (Fig. 14), the model currents are in approximate agreement with the observed currents at middepth, but stronger than those observed near the surface.

\section{d. Spring (April-May) and fall (October-November)}

The spring (Fig. 10b) and fall (Fig. 10d) composite solutions also show cyclonic circulation in the gulf and southwestward flows over the shelf, similar to their summer and winter counterparts. However, they also have some distinct features associated primarily with contrasts in the near-surface baroclinic pressure gradients and in the inflows across the SBI and SNS boundaries.

In spring (Fig. 10b) the SBI inflow of $0.2 \mathrm{~Sv}$ lies between the winter and summer values, and is comparable to Petrie et al.'s (1988) observational estimate of $0.3 \mathrm{~Sv}$ (Table 2). The Gaspé Current has its annual maximum speed of about $150 \mathrm{~cm} \mathrm{~s}^{-1}$ near the Gaspé coast (Fig. 12a), consistent with Benoit et al. (1985). The peak transport and north-south structure of the cyclonic gyre in the northwest gulf are similar to summer and winter. The predominantly baroclinic outflow on the western side of Cabot Strait has a transport of $1.0 \mathrm{~Sv}$ and an annual minimum peak speed of $15 \mathrm{~cm} \mathrm{~s}^{-1}$, while

FIG. 13. (Continued) barotropic SNS inflows (dashed curves) are included. Here u and v are the eastward and northward components, respectively. The horizontal lines indicate the standard deviations of the individual observed monthly means about the bimonthly means. The site locations are shown in Fig. 4. Note that there are two CSE sites; the curves below the 200-m depth are for the northern site. 
the primarily barotropic inflow on the strait's eastern side has a transport of $0.8 \mathrm{~Sv}$ (Fig. 12b; Table 2).

The Nova Scotian Current is in an intermediate stage between its winter maximum and summer minimum transports, including flows from Cabot Strait onto both the inner $(0.3 \mathrm{~Sv})$ and middle $(0.1 \mathrm{~Sv})$ ESS (Fig. 12c) but a transport of only $0.2 \mathrm{~Sv}$ downstream on the inner Liscomb line (Table 2). There is again a strong southwestward shelf-break current on the ESS, with peak speed exceeding $30 \mathrm{~cm} \mathrm{~s}^{-1}$ and transport exceeding 3 Sv. On the SNS, the shelf transport pattern (Fig. 10b) is similar to that in summer while the shelf-edge transport is similar to that in winter (Table 2).

The current comparison statistics (Table 3) indicate poor agreement between the model and observed currents for spring, but note that the observational dataset is smaller than in winter or summer. Considering the overall similarity of the spring solution to those in winter and summer, it is unclear whether the poor agreement reflects inadequacies in the model solution or in the observational dataset.

In fall (Fig. 10d) the SBI inflow has its maximum transport value of $0.5 \mathrm{~Sv}$, consistent with the timing of the Labrador Current over the Labrador Shelf (Lazier and Wright 1993). Some of this transport reinforces the Gaspé Current which has a peak speed of $50 \mathrm{~cm} \mathrm{~s}^{-1}$ in fall (Fig. 12a). The outflow through Cabot Strait reaches an annual maximum value of $1.3 \mathrm{~Sv}$ with a peak speed of $45 \mathrm{~cm} \mathrm{~s}^{-1}$ and covers most of the western two-thirds of the strait with strong surface intensification (Fig. 12b, Table 2). The inflow to the gulf has a transport of 0.8 $\mathrm{Sv}$ and is again dominated by the barotropic flow near the Newfoundland coast.

The Nova Scotian Current in fall $(0.3 \mathrm{~Sv}$ on the inner Liscomb line) is again in an intermediate phase of its seasonal evolution. The transport from Cabot Strait directly onto the inner ESS has its annual peak in this season $(0.6 \mathrm{~Sv})$, but some of this flow moves to the shelf edge east of Sable Island (Fig. 10d). There is again a strong southwestward artery at the ESS edge with peak speed exceeding $30 \mathrm{~cm} \mathrm{~s}^{-1}$ and a transport of $2.6 \mathrm{~Sv}$, with contributions from both Cabot Strait and the SNS. However, the SNS-SB inflow is particularly uncertain in fall because of suspect small-scale hydrographic structure associated with data sparsity (e.g., Fig. 10d).

The current comparison statistics (Table 3) suggest fair-to-good quantitative agreement, comparable to that in summer in spite of the much smaller observational dataset.

\section{Discussion}

\section{a. Roles of upstream inflows versus local} baroclinicity

Conceptually, the major components of the depthintegrated seasonal circulation in the gulf-shelf system can be identified as barotropic (i.e., with nonzero geo- strophic bottom currents) inflows, baroclinic inflows, and local baroclinic flows (in practice, these are often interrelated). The available observational data and the present model solutions suggest that all three of these are important contributors. The density distributions in the vicinity of major current features, such as the Gaspé Current and the Cabot Strait flows (Fig. 6), and the observed current shears (Figs. 13, 14) suggest that baroclinic pressure gradients are a major forcing. The present solutions suggest that these gradients are primarily associated with baroclinic pressure field features within the study domain since the baroclinic transports across the upstream boundaries are generally less than (or reversed from) the barotropic boundary transports (compare the SNS transports from the composite barotropic case in Table 1 with those in Table 2). The solutions also indicate that barotropic inflows through the SBI make significant contributions in the gulf and along the ESS edge, particularly in fall and winter, and that there is the potential for significant influences from barotropic inflows along the SNS edge (e.g., substantial improvement on the model-observation agreement at Cabot Strait and over the outer ESS). It is clear that barotropic inflows across both upstream boundaries can have especially important influences in coupling the gulf and shelf and in providing an overall throughflow to downstream regions. However, the historical observational data are not adequate to determine the magnitude and barotropic-baroclinic partitioning of the major SNS inflow associated with Labrador Current penetration around the Grand Bank. In fact, the present observational evidence is somewhat contradictory in that the inclusion of barotropic SNS inflow improves both the Cabot Strait transports and certain ESS velocity profiles but degrades global difference ratios in spring, summer, and fall. Recent current and hydrographic observations on the SNS should be particularly helpful in sorting out some of these discrepancies.

The various model solutions indicate that wind forcing and tidal rectification are smaller contributors to the overall seasonal circulation in the gulf-shelf system, although wind forcing is important to the near-surface flow in all seasons and makes a significant barotropic contribution in winter and tidal rectification is important in local areas such as the LSLE.

\section{b. Observational evaluation of model fields}

A critical factor to interpreting the model flow fields is their consistency with the seasonal circulation in the ocean. A major difficulty is the uncertainty in observational estimates of the climatological seasonal-mean currents and transports, given the limited duration and sites of current measurements and the substantial spatial and temporal (monthly, interannual) variability of ocean currents. This is reflected in the large standard deviations (of monthly means about seasonal means) on many of the observational current estimates in Fig. 13. Further, 
a significant limitation in the realism and reliability of the present flow fields results from the combination of the diagnostic methodology (i.e., no evolution of density) and sparsely distributed density observations. This can result in artificial small-scale flow features (e.g., associated with density gradients due to aliased temporal variability), which may dominate some of the local current comparisons, as well as contaminate some of the model transport estimates. Clearly, such features may limit the reliability of the present model flow fields for applications such as particle tracking and exact transport estimates. In general, integrated measures of the flow fields such as the transport estimates (Fig. 10, Table 2) are less severely affected and provide observationally based quantitative descriptions of the major circulation features, but the small-scale structures and suspect transport estimates over the SNS slope illustrate local limitations.

\section{c. Horizontal versus vertical structure of estuarine circulation}

The hydrographic property distributions (Figs. 5, 6) suggest a vertically structured overall circulation pattern for the gulf-shelf system, with high salinity water penetrating at depth into the gulf at all positions in the Laurentian Channel. However, the composite base velocity fields (e.g., Fig. 12) have a more horizontally structured flow pattern as expected for a wide estuary, with flow generally into the gulf throughout the water column on the eastern side of Cabot Strait and a tendency for flow out of the gulf throughout the water column on its western side. The latter includes outflow of the deep high-salinity water on the western side of the Laurentian Channel (Fig. 6), which raises questions regarding the consistency of the diagnostic flow fields with the hydrography, and the processes contributing to slope water penetration into the gulf. A contributing factor to the horizontally structured flows in the model is the additional SBI and SNS barotropic inflows (Fig. 7), which contribute to the deep flows on the western side of the Laurentian Channel flowing seaward (but deep seaward flows are also present in the solutions without the additional barotropic inflows). Possible explanations for this apparent inconsistency include substantial horizontal recirculations and/or dispersion within the high-salinity deep layer, overestimation of the additional barotropic flows in the present solutions, and/ or underestimation of the baroclinic flows (e.g., due to excessive horizontal smoothing of the density fields). Recent field measurements in the CS and SNS edge regions should be of particular value in resolving the overall barotropic-baroclinic partitioning of the system's circulation and the critical vertical and horizontal structure of the flow in the Cabot Strait region.

\section{Concluding remarks}

The climatological seasonal-mean hydrography and associated circulation in the Gulf of St. Lawrence and over the eastern Scotian and southern Newfoundland shelves suggest important gulf-shelf connections, pronounced topographic influences, substantial year-round persistence, and significant seasonal and regional variability. Gulf-shelf hydrographic communication is clearly apparent in the surface and bottom fields, with a near-surface seaward advection of lighter waters and a deep shoreward penetration of North Atlantic slope water. On the other hand, the hydrographic distributions suggest notable regional regimes: 1) the Gulf of St. Lawrence (strongly influenced by freshwater runoff), Labrador and southern Newfoundland shelf waters, and slope water; 2) the southern Newfoundland shelf, predominantly influenced by the upstream Newfoundland shelf; and 3) the eastern Scotian shelf, with major influences from both the Gulf of St. Lawrence (inner and outer shelf) and the southern Newfoundland shelf (along the shelf break).

The diagnostic model flow fields provide a first quantitative description from an integrated gulf-shelf perspective of the seasonal-mean circulation implied by various observational datasets. The circulation consists of throughflows from the north (Strait of Belle Isle) and east (southern Newfoundland shelf) with an overall cyclonic flow tendency over deep areas that is locally intensified in parts of the gulf. The throughflows have seasonal variations and include baroclinic and barotropic components although the structure of the inflow from the southern Newfoundland shelf is poorly known. The Gaspé Current and the Nova Scotian Current in the model solutions are in good agreement with moored measurements and are insensitive to the barotropic throughflows. The seasonally varying inflow through the Strait of Belle Isle results in a seasonal variation in the Cabot Strait net transport (with the plausible assumption that the gulf's adjustment timescale is less than a season). The inflow from the southern Newfoundland shelf to the Scotian shelf varies seasonally, with the present solutions indicating year-round flow along the shelf break, and an additional indirect route via the Gulf of St. Lawrence. The base solutions include a seasonally invariant barotropic inflow of $2.3 \mathrm{~Sv}$ on the southern Newfoundland shelf slope, which reduces the modelobservation mismatch at Cabot Strait and over the outer Scotian shelf break, but whose veracity needs further evaluation. With this barotropic inflow included, the southwestward shelf-edge (inside the 1000-m isobath) transport across the downstream boundary varies from 2.2 Sv in summer to $3.1 \mathrm{~Sv}$ in winter and spring (Table 2 ), while without it the transport varies from 0.3 to 1.2 $\mathrm{Sv}$, pointing to the implications of uncertainty in this flow component for downstream regions. Transport of water from the Gulf of St. Lawrence onto the Scotian shelf occurs year-round as a seasonally varying (but 
poorly understood) trifurcation with branches onto the inner, middle, and outer shelf. Important vertical structure in the seasonal-mean circulation is indicated, with the moored current measurements generally supporting the present choice (through the steric component of the upstream boundary conditions) of reduced flow strength near the bottom (i.e., surface intensification of the circulation). However, the apparent shoreward penetration of high salinity water at depth all across Cabot Strait and the Laurentian Channel suggests greater vertical flow structure than in the present solutions, pointing to either additional processes involved in the slope water penetration or overestimation of the barotropic flow. Additional current measurements are certainly needed for a better determination of the circulation, particularly in key areas such as Cabot Strait and the southern Newfoundland shelf edge.

While the study results demonstrate the value of numerical circulation models in providing a quantitative representation of the seasonal mean circulation, the model solutions also indicate expected limitations in the applicability of diagnostic circulation models to areas with limited historical data coverage (relative to spatial and temporal density variations). These limitations include some local recirculation features, which may include artificial contributions from aliased density structures over topography, and possible inconsistencies between the flow and density fields such as for the deep slope water in Cabot Strait. These limitations may be partially mitigated by additional observational (hydrography, currents, and elevation) data and improvements in the baroclinic pressure field estimation method, but prognostic models with coupled density and momentum equations are required to provide circulation fields with increased reliability and self-consistency. The study also points to a long-standing difficulty in regional numerical model applications: uncertainty in the open boundary conditions. Moored measurements in key areas and/or data-assimilation schemes can provide improvements to the present choice of boundary conditions, particularly on the southern Newfoundland shelf.

Acknowledgments. We are indebted to Ken Drinkwater and Roger Pettipas for their lead role in the database assembly, Dan Lynch and Chris Naimie for providing the numerical model and related algorithms, Mary Jo Graca for assistance in the hydrographic field computations, Dave Greenberg and Charles Hannah for advice on the model, Elizabeth Gonzalez for assistance with plots, and Gary Bugden and Charles Tang for internal review comments on the manuscript. We thank two anonymous reviewers for their constructive comments and suggestions. This work has been funded through the Cod/Redfish (CORE) Project of the Department of Fisheries and Oceans, and the Federal Panel for Energy, Research and Development.

\section{REFERENCES}

Anderson, C., and P. C. Smith, 1989: Oceanographic observations on the Scotian Shelf during CASP. Atmos.-Ocean, 27, 130-156.

Benoit, J., M. I. El-Sabh, and C. L. Tang, 1985: Structure and seasonal characteristics of the Gaspé Current. J. Geophys. Res., 90 (C2), 3225-3236.

Bourque, M.-C., and D. Kelley, 1995: Evidence of wind-driven upwelling in Jacques-Cartier Strait. Atmos.-Ocean, 33, 621-637.

Bretherton, F. P., R. E. Davis, and C. B. Fandry, 1976: A technique for objective analysis and design of oceanographic experiments applied to MODE-73. Deep-Sea Res. I, 23, 559-582.

Bugden, G. L., 1981: Salt and heat budgets for the Gulf of St. Lawrence. Can. J. Fish. Aquat. Sci., 38, 1153-1167.

- 1991: Changes in the temperature-salinity characteristics of the deeper waters of the Gulf of St. Lawrence over the past several decades. Can. Spec. Publ. Fish. Aquat. Sci., 113, 139147.

Campana, S. E., J. A. Gagne, and J. W. McLaren, 1995: Elemental fingerprinting of fish otoliths using ID-ICPMS. Marine Ecology Progress Series, Vol. 122, 115-120.

Chapman, D. C., and R. C. Beardsley, 1989: On the origin of shelf water in the Middle Atlantic Bight. J. Phys. Oceanogr., 19, 384391.

Csanady, G. T., 1978: The arrested topographic wave. J. Phys. Oceanogr., 8, 47-62.

- and P. Hamilton, 1988: Circulation of slopewater. Contin. Shelf Res., 8, 565-624.

Dawson, W. B., 1913: The Currents in the Gulf of St. Lawrence. Department of Naval Sciences, $46 \mathrm{pp}$.

Drinkwater, K. F., and R. W. Trites, 1986: Monthly means of temperature and salinity in the Grand Banks region. Can. Tech. Rep. Fish. Aquat. Sci., 1450, iv +111 pp.

$\ldots$, and -1987 : Monthly means of temperature and salinity in the Scotian Shelf region. Can. Tech. Rep. Fish. Aquat. Sci., 1539, iv $+101 \mathrm{pp}$.

- B. Petrie, and W. H. Sutcliffe, 1979: Seasonal geostrophic volume transport along the Scotian Shelf. Estuar. Coastal Mar. Sci., 9, 17-27.

El Sabh, M. I., 1976: Surface circulation patterns in the Gulf of St. Lawrence. J. Fish. Res. Board Can., 34, 516-528.

_ 1977: Oceanographic features, currents and transport in Cabot Strait. J. Fish. Res. Board Can., 33, 124-138.

— tuarine System. The St. Lawrence. Vol. 39, Coastal Estuarine Studies, Springer-Verlag, $434 \mathrm{pp}$.

Gatien, M. G., 1976: A study in the slope water region south of Halifax. J. Fish. Res. Board. Can., 33, 2213-2217.

Gilbert, D., and B. Pettigrew, 1997: Interannual variability (19481994) of the CIL core temperature in the Gulf of St. Lawrence. Can. J. Fish. Aquat. Sci., 54 (Suppl. 1), 57-67.

Greenberg, D. A., and B. D. Petrie, 1988: The mean barotropic circulation on the Newfoundland Shelf and Slope. J. Geophys. Res., 93, 15 541-15 550.

Hachey, H. B., 1942: The waters of the Scotian Shelf. J. Fish. Res. Board Can., 5, 377-397.

Han, G., and P. C. Smith, 1997: Annual variation of sea surface elevations and currents over the Scotian Shelf and the Grand Banks from the TOPEX/POSEIDON altimetry. Ann. Geophys., 15 (Suppl. II), 402.

- M. Ikeda, and P. C. Smith, 1993: Annual variation of sea-surface slopes over the Scotian Shelf and Grand Banks from Geosat altimetry. Atmos.-Ocean, 31, 591-615.

- P. C. Smith, and J. W. Loder, 1996: Hydrography and circulation in the Gulf of St. Lawrence and eastern Scotian and southern Newfoundland Shelves. Eos., Trans. Amer. Geophys. Union, 77 (46), 348.

- C. G. Hannah, J. W. Loder, and P. C. Smith, 1997: Seasonal variation of the three-dimensional mean circulation over the Scotian Shelf. J. Geophys. Res., 102 (C1), 1011-1025. 
Hannah, C. G., J. W. Loder, and D. G. Wright, 1996: Seasonal variation of the baroclinic circulation in the Scotia-Maine region. Vol. 53, Boundary Effects on Coastal Dynamics, D. G. Aubrey, Ed., Amer. Geophys. Union, 7-29.

Herman, A. W., D. D. Sameoto, C. Shunnian, M. R. Mitchell, B. Petrie, and N. Cochrane, 1992: Sources of zooplankton on the Nova Scotia Shelf and other aggregations within the deep shelf basins. Contin. Shelf Res., 11, 211-238.

Koutitonsky, V. G., and G. L. Bugden, 1991: The physical oceanography of the Gulf of St. Lawrence: A review with emphasis on the synoptic variability of the motion. Can. Spec. Publ. Fish. Aquat. Sci., 113, 57-90.

Lawrence, D. J., 1968: Current meter data from Cabot Strait, 1966. BI Data Series 1968-10-D, Bedford Institute of Oceanography, Unpublished manuscript.

Lazier, J. R. N., and D. G. Wright, 1993: Annual velocity variations in the Labrador Current. J. Phys. Oceanogr., 23, 659-678.

Loder, J. W., G. Han, C. G. Hannah, D. A. Greenberg, and P. C. Smith, 1997: Hydrography and baroclinic circulation in the Scotian Shelf region: Winter vs summer. Can. J. Fish. Aquat. Sci., 54 (Suppl. 1), 40-56.

- B. D. Petrie, and G. Gawarkiewicz, 1998: The coastal ocean off northeastern North America: A large-scale view, Ch. 5. The Global Coastal Ocean: Regional Studies and Synthesis. Vol. 11, The Sea, K. H. Brink and A. R. Robinson, Eds., John Wiley and Sons, in press.

Lynch, D. R., F. E. Werner, D. A. Greenberg, and J. W. Loder, 1992: Diagnostic model for the baroclinic, wind-driven and tidal circulation in shallow seas. Contin. Shelf Res., 12, 37-64.

MacGregor, D. G., 1956: Currents and transport in Cabot Strait. J. Fish. Res. Board Can., 13, 435-448.

McLellan, H. J., 1954: Bottom temperature on the Scotian Shelf. J. Fish. Res. Board Can., 11, 404-418.

Morin, B., D. Power, and P. Gagnon, 1994: Distribution of redfish (Sebastes spp.) in the Gulf of St. Lawrence and in the Laurentian Channel based on RV surveys and commercial fishery catch rates. DFO Atlantic Fisheries Research Document 94/91, 52 pp. [Available from Bedford Institute of Oceanography, Dartmouth, NS B2Y 4A2 Canada.]

Murty, T. S., and J. D. Taylor, 1970: A numerical calculation of the wind-driven circulation in the Gulf of St. Lawrence. J. Oceanogr Soc. Japan, 26, 203-214.

Naimie, C. E., and D. R. Lynch, 1993: FUNDY5 Users' Manual. Numerical Methods Laboratory, Dartmouth College, NH, 40 pp. [Available from Dartmouth College, Hanover, NH 03755.]
- J. W. Loder, and D. E. Lynch, 1994: Seasonal variation of the three-dimensional residual circulation on Georges Bank. J. Geophys. Res., 99, 15 967-15989.

Petrie, B. D., and K. Drinkwater, 1993: Temperature and salinity variability on the Scotian Shelf and in the Gulf of Maine 19451990. J. Geophys. Res., 98, 20 079-20 089.

, B. J. Topliss, and D. G. Wright, 1987: Coastal upwelling and eddy development off Nova Scotia. J. Geophys. Res., 92, 12 979-12 991.

— - B. Toulany, and C. Garrett, 1988: The transport of water, heat and salt through the Strait of Belle Isle. Atmos.-Ocean, 26, 234251

—, K. Drinkwater, A. Sandstrom, R. Pettipas, D. Gregory, D. Gilbert, and P. Sekhon, 1996: Temperature, salinity and sigma-t atlas for the Gulf of St. Lawrence. Can. Tech. Rep. Hydrogr. Ocean Sci., 178, v + 256 pp.

Sameoto, D. D., and A. W. Herman, 1992: Effect of the outflow from the Gulf of St. Lawrence on the Scotia Shelf Zooplankton. Can. J. Fish. Aquat. Sci., 49, 857-869.

Smith, P. C., 1987: The distribution of surface wind over the Scotian Shelf. Proc. Int. Workshop on Wave Hindcasting and Forecasting, Dartmouth, NS, Environmental Studies Revolving Fund, Report Series 065, 370 pp. [Available from Bedford Institute of Oceanography, Dartmouth, NS B2Y 4A2 Canada.]

- and B. D. Schwing, 1991: Mean circulation and variability on the eastern Canadian continental shelf. Contin. Shelf Res., 11, 977-1012

_ B. Petrie, and C. R. Mann, 1978: Circulation, variability and dynamics of the Scotian Shelf and Slope. J. Fish. Res. Board Can., 35, 1067-1083.

Sutcliffe, W. H., R. H. Loucks, and K. F. Drinkwater, 1976: Coastal circulation and physical oceanography of the Scotian Shelf and Gulf of Maine. J. Fish. Res. Board Can., 33, 98-115.

Tang, C. L., 1980: Mixing and circulation in the northwestern Gulf of St. Lawrence: A study of a buoyancy-driven current system. J. Geophys. Res., 85, 2787-2796.

Trites, R. W., 1972: The Gulf of St. Lawrence from a pollution point of view. Marine Pollution and Sea Life, M. Ruivo, Ed., Fishing News Books, 59-72.

—, D. R. McLain, and M. C. Ingham, 1985: Sea surface temperatures along the continental shelf from Cape Hatteras to Hamilton Bank. NAFO Sci. Coun. Stud., 8, 21-23.

Umoh, J. U., and K. R. Thompson, 1994: Surface heat flux, horizontal advection, and the seasonal evolution of water temperature on the Scotian Shelf. J. Geophys. Res., 99, $20403-20416$. 
